\title{
Nicotinic Receptor Subtype-Selective Circuit Patterns in the Subthalamic Nucleus
}

\author{
[CCheng Xiao, ${ }^{1}$ Julie M. Miwa, ${ }^{1,2}$ Brandon J. Henderson, ${ }^{1}$ Ying Wang, ${ }^{1}$ Purnima Deshpande, ${ }^{1}$ Sheri L. McKinney, ${ }^{1}$ \\ and ${ }^{\circ}$ Henry A. Lester ${ }^{1}$ \\ ${ }^{1}$ Division of Biology and Biological Engineering, California Institute of Technology, Pasadena, California 91125, and ${ }^{2}$ Department of Biological Sciences, \\ Lehigh University, Bethlehem, Pennsylvania 18015
}

The glutamatergic subthalamic nucleus (STN) exerts control over motor output through nuclei of the basal ganglia. High-frequency electrical stimuli in the STN effectively alleviate motor symptoms in movement disorders, and cholinergic stimulation boosts this effect. To gain knowledge about the mechanisms of cholinergic modulation in the STN, we studied cellular and circuit aspects of nicotinic acetylcholine receptors (nAChRs) in mouse STN. We discovered two largely divergent microcircuits in the STN; these are regulated in part by either $\alpha 4 \beta 2$ or $\alpha 7 \mathrm{nAChRs.} \mathrm{STN} \mathrm{neurons} \mathrm{containing} \alpha 4 \beta 2 \mathrm{nAChRs} \mathrm{(} \alpha 4 \beta 2$ neurons) received more glutamatergic inputs, and preferentially innervated GABAergic neurons in the substantia nigra pars reticulata. In contrast, STN neurons containing $\alpha 7 \mathrm{nAChRs}(\alpha 7$ neurons) received more GABAergic inputs, and preferentially innervated dopaminergic neurons in the substantia nigra pars compacta. Interestingly, local electrical stimuli excited a majority (79\%) of $\alpha 4 \beta 2$ neurons but exerted strong inhibition in 58\% of $\alpha 7$ neurons, indicating an additional diversity of STN neurons: responses to electrical stimulation. Chronic exposure to nicotine selectively affects $\alpha 4 \beta 2 \mathrm{nAChRs} \mathrm{in} \mathrm{STN:} \mathrm{this} \mathrm{treatment} \mathrm{increased} \mathrm{the} \mathrm{number} \mathrm{of} \alpha 4 \beta 2$ neurons, upregulated $\alpha 4$-containing $\mathrm{nAChR}$ number and sensitivity, and enhanced the basal firing rate of $\alpha 4 \beta 2$ neurons both ex vivo and in vivo. Thus, chronic nicotine enhances the function of the microcircuit involving $\alpha 4 \beta 2 \mathrm{nAChRs}$. This indicates chronic exposure to nicotinic agonist as a potential pharmacological intervention to alter selectively the balance between these two microcircuits, and may provide a means to inhibit substantia nigra dopaminergic neurons.

Key words: alpha4beta2; alpha7; chronic nicotine; Parkinson's disease; substantia nigra; upregulation

\section{Introduction}

The subthalamic nucleus (STN), through glutamatergic synapses, governs two output nuclei of the basal ganglia: the internal segment of the globus pallidus and the substantia nigra pars reticulata (SNr) (Smith and Parent, 1988; Heida et al., 2008; Marani et al., 2008). Parkinson's disease (PD) is caused by the death of dopaminergic (DA) neurons in the substantia nigra pars compacta $(\mathrm{SNc})$ and is characterized by motor symptoms, such as resting tremor, rigidity, bradykinesia, and akinesia. STN neurons in PD show abnormal activity, including accelerated, burst, and synchronized firing, which are correlated with motor symptoms (Bergman et al., 1994; Wichmann et al., 1994; Kreiss et al., 1997; Magnin et al., 2000; Perlmutter and Mink, 2006; Weinberger et al., 2009). Dopamine compensation with L-dopa or apomorphine relieves motor symptoms and restores normal activity in

\footnotetext{
Received Aug. 17, 2014; revised Jan. 5, 2015; accepted Jan. 14, 2015.

Author contributions: C.X., Y.W., and H.A.L. designed research; C.X. and Y.W. performed research;P.D. and S.L.M. contributed unpublished reagents/analytic tools; C.X. and H.A.L. analyzed data; C.X., J.M.M., B.J.H., and H.A.L. wrote the paper.

This work was supported by National Institutes of Health Grants DA17279, AG033954, and R21DA033831, and the California Tobacco-Related Disease Research Program Grants 16FT-0066, 17RT-0127, and 19KT-0032. We thank Raad Nashmi and Haijiang Cai for comments and discussion.

The authors declare no competing financial interests.

Correspondence should be addressed to Dr. Henry A. Lester, Mail code 156-29, California Institute of Technology, 1200 East California Blvd, Pasadena, CA 91125. E-mail: lester@caltech.edu.

DOI:10.1523/JNEUROSCI.3528-14.2015

Copyright $\odot 2015$ the authors $\quad 0270-6474 / 15 / 353734-13 \$ 15.00 / 0$
}

STN neurons (Kreiss et al., 1997; Levy et al., 2001, 2002; Weinberger et al., 2006). As PD progresses, L-dopa efficacy decreases; however, increasing L-dopa dosage causes motor fluctuations and dyskinesia (Perlmutter and Mink, 2006; Cenci, 2007; Poewe, 2009). Therefore, it is important to identify other therapies aiming to enhance or maintain L-dopa efficacy to minimize these side effects.

Deep brain stimulation (DBS) in the STN not only improves the major motor symptoms of PD but also reduces required doses of L-dopa and mitigates motor fluctuations and dyskinesia (Nutt et al., 2001; Breit et al., 2004; Perlmutter and Mink, 2006; Benabid et al., 2009; Gradinaru et al., 2009). Cholinergic neurons in the pedunculopontine tegmental nucleus (PPTg) project to STN (Ichinohe et al., 2000; Benarroch, 2008), and clinical data show that stimulating these neurons boosts the therapeutic effects of STN DBS (Stefani et al., 2007). Additionally, long-term use of nicotinic agonists potentiates the ability of L-dopa to improve motor symptoms (Schneider et al., 1998; Domino et al., 1999) and attenuates L-dopa-induced dyskinesia (Quik et al., 2007; Bordia et al., 2008; Huang et al., 2011). These facts suggest that cholinergic agonists and DBS may target the same neuron types in STN.

Nicotinic acetylcholine receptors (nAChRs) in the basal ganglia help to govern voluntary movement (Dani and Bertrand, 2007; Miwa et al., 2011; Quik and Wonnacott, 2011). Mice carrying gain-of-function or null mutations in nAChR subunits al- 
low selective activation or deletion of certain nAChR subtypes in vivo (Champtiaux and Changeux, 2002; Lester et al., 2003). Studies using these mouse lines implicate nAChRs containing $\alpha 4, \alpha 6$, and $\beta 2$ subunits in the control of movement (Labarca et al., 2001; Tapper et al., 2004; Drenan et al., 2008, 2010; Drenan and Lester, 2012). It is well established that these nAChRs modulate neuronal activity and neurotransmitter release in the SN and the striatum (Nashmi et al., 2007; Drenan et al., 2008, 2010; Xiao et al., 2009a; Quik and Wonnacott, 2011). However, how these nAChRs regulate other nuclei in the basal ganglia is understood poorly.

Although several nAChR subunit mRNAs and binding sites have been detected in the STN (Cimino et al., 1992; Quik et al., 2000; Pimlott et al., 2004), it remains unclear whether nAChRs subtypes modulate the divergent outputs of STN neurons and whether chronic exposure to nicotine regulates these nAChRs and modifies neural circuits. In this study, we addressed these questions.

\section{Materials and Methods}

The care and use of animals and the experimental protocol of this study were approved by the Institutional Animal Care and Use Committee of the California Institute of Technology. Efforts were made to minimize animal suffering and to minimize the number of animals used.

Electrophysiological recordings: brain slice preparation. The recordings were performed using brain slices, which were prepared from 7- to 11week-old C57BL/6 (wild-type) mice, nAChR $\alpha 4$-YFP, or $\alpha 4$ subunit knock-out mice, using the protocol described with some modifications (Ye et al., 2006; Xiao et al., 2009a, b). Both $\alpha 4-\mathrm{KO}$ and $\alpha 4$-YFP mice were backcrossed $>\mathrm{N} 10$ to $\mathrm{C} 57 \mathrm{BL} / 6$. In brief, the mice were killed with $\mathrm{CO}_{2}$ and were subject to cardiac perfusion with ice-cold modified glycerolbased artificial CSF saturated with $95 \% \mathrm{O}_{2} / 5 \% \mathrm{CO}_{2}$ (carbogen) containing the following (in mM): 250 glycerol, $2.5 \mathrm{KCl}, 1.2 \mathrm{NaH}_{2} \mathrm{PO}_{4}, 1.2$ $\mathrm{MgCl}_{2}, 2.4 \mathrm{CaCl}_{2}, 26 \mathrm{NaHCO}_{3}$, and 11 glucose. The brain was subsequently removed and sliced with a microslicer (DTK-1000, Ted Pella) or a Compresstome (VH-200, Precisionary) while immersed in modified glycerol-based artificial CSF. To retain the connection between STN and the substantia nigra $(\mathrm{SN})$, we cut parasagittal slices $(350 \mu \mathrm{m})$ with an inward angle of $10^{\circ}-14^{\circ}$ toward the forebrain. Brain slices, containing STN and the SN, were allowed to recover at $32^{\circ} \mathrm{C}$ in a holding chamber filled with carbogenated artificial CSF, containing the following (in $\mathrm{mM}$ ): $125 \mathrm{NaCl}, 2.5 \mathrm{KCl}, 1.2 \mathrm{NaH}_{2} \mathrm{PO}_{4}, 1.2 \mathrm{MgCl}_{2}, 2.4 \mathrm{CaCl}_{2}, 26 \mathrm{NaHCO}_{3}$, and 11 glucose. One hour later, the holding chamber with slices was placed at room temperature. One of the slices was transferred into the recording chamber and superfused $(1.5-2.0 \mathrm{ml} / \mathrm{min})$ with carbogensaturated artificial CSF at $32 \pm 0.5^{\circ} \mathrm{C}$. Three or four slices per mouse were used for recordings.

Patch-clamp recording. The neurons were visualized with an upright microscope (BX50WI; Olympus) and near infrared or blue illumination (the latter for visualizing fluorescent proteins). Single or dual whole-cell patch-clamp techniques were used to record electrophysiological signals from neurons with MultiClamp 700B amplifiers (Molecular Devices), Digidata 1322 analog-to-digital converters (Molecular Devices), and pClamp 9.2 software (Molecular Devices). Data were sampled at $10 \mathrm{kHz}$ and filtered at $2 \mathrm{kHz}$. A patch electrode had a resistance of $4-6 \mathrm{M} \Omega$, when filled with intrapipette solutions: solution 1 (in $\mathrm{mM}$, for most experiment): $135 \mathrm{~K}$ gluconate, $5 \mathrm{KCl}, 5 \mathrm{EGTA}, 0.5 \mathrm{CaCl}_{2}, 10 \mathrm{HEPES}, 2 \mathrm{Mg}$-ATP, and 0.1 GTP; solution 2 (in $\mathrm{mM}$, for particular experiments as stated): 70 K gluconate, $65 \mathrm{KCl}, 5 \mathrm{EGTA}, 0.5 \mathrm{CaCl}_{2}$, 10 HEPES, $2 \mathrm{Mg}$-ATP, $0.1 \mathrm{GTP}$, and $2 \mathrm{~mm}$ QX-314. The $\mathrm{pH}$ of these solutions was adjusted to 7.2 with Tris-base, and their osmolarity was adjusted to $300 \mathrm{mOsm}$ with sucrose. The junction potential between patch pipette and bath solutions was nulled just before gigaseal formation. Series resistance was monitored without compensation throughout the experiment using the Multiclamp 700B. The data were discarded if the series resistance (15-30 $\mathrm{M} \Omega$ ) changed by $>20 \%$ during whole-cell recordings.

The bath was continually perfused with artificial CSF. All recordings were done at a temperature of $32 \pm 1^{\circ} \mathrm{C}$.
Anterograde neuronal tracing. Male adult C57BL/6 mice (3-4 months old) were anesthetized with isoflurane ( $4 \%$ for induction, $1.5 \%-2 \%$ for maintenance), placed on a heating pad, and immobilized on a stereotaxic frame (Stoelting) (Xiao et al., 2009a). An incision was made in the skin of the head to expose the skull, and a 0.4-mm-diameter hole, centered at 1.5 $\mathrm{mm}$ caudal to bregma and $1.5 \mathrm{~mm}$ right from midline, was drilled on the skull. The dura was torn with a sharp needle. A glass pipette with 50-60 $\mu \mathrm{m}$ tip was filled with $3 \%$ biotinylated-dextran amine (BDA-10,000, in saline), an anterograde tracer (Invitrogen), was held on a Hamilton syringe and mounted onto a microinjector (WPI). BDA $(0.1 \mu \mathrm{l})$ was bilaterally injected in a spot (anteroposterior $1.5 \mathrm{~mm}$; lateral $1.5 \mathrm{~mm}$; dorsoventral $4.8 \mathrm{~mm}$ ) in $5 \mathrm{~min}$, and the glass pipette was gradually lifted up after injection. Each mouse was allowed to recover for $21 \mathrm{~d}$ before histology assay.

In vivo single-unit recording. Male adult C57BL/6 mice (3-4 months old) were anesthetized with chloral hydrate $(400 \mathrm{mg} / \mathrm{kg}$, i.p.), placed on a heating pad, and mounted on a stereotaxic frame (Stoelting) (Xiao et al., 2009a). The skin of the head was opened to expose the skull, and a 2 -mm-diameter hole, centered at $1.5 \mathrm{~mm}$ caudal to bregma and $1.5 \mathrm{~mm}$ right from midline, was drilled in the skull. The dura was torn with a sharp needle. Chloral hydrate was intraperitoneally injected at $100 \mathrm{mg} /$ $\mathrm{kg} / 30 \mathrm{~min}$ to maintain deep anesthesia (loss of toe pinch reflex).

Electrodes with a $3 \mu \mathrm{m}$ tip were pulled from thick-wall borosilicate glass (WPI) with a horizontal micropipette puller (Sutter Instruments). When filled with $2 \mathrm{M} \mathrm{NaCl}$, the electrodes had resistance of $2-5 \mathrm{M} \Omega$. The signals were amplified with Axoclamp 2A (Molecular Devices) and Brownlee Precision (model 440) amplifiers, sampled at $10 \mathrm{kHz}$ with Digidata 1200 (Molecular Devices), controlled by pClamp 9.2 (Molecular Devices) software. We searched for spikes at the coordinates (lateral: 1.3, 1.5, $1.7 \mathrm{~mm}$; bregma: $-1.6,-1.8,-2.0 \mathrm{~mm}$; ventral from bregma: $4.3-$ $4.75 \mathrm{~mm}$ ), according to the parasagittal planes in a mouse brain atlas (Paxinos and Franklin, 2001).

To confirm the recording sites, we added $0.2 \%$ neurobiotin in the intrapipette solution $(2 \mathrm{M} \mathrm{NaCl})$, and injected $10 \mathrm{nA}(5 \mathrm{~min})$ using an Axoclamp 2A amplifier, at the end of each experiment. We performed histochemistry to visualize neurobiotin (see Fig. 5A). The neurobiotin location was defined according to the mouse brain atlas and was used to calibrate our recording coordinates.

In some experiments, we applied acetylcholine (ACh) by iontophoresis. The recording/stimulating electrode contained $0.5 \mathrm{M} \mathrm{ACh}$ in $2 \mathrm{M}$ $\mathrm{NaCl}$. We applied a $-5 \mathrm{nA}$ current to prevent ACh from leaking, and ACh was applied by $30 \mathrm{nA}$ current injection (Armstrong and Lester, 1979).

Immunohistochemistry. The C57BL/6 mice and $\alpha 4$-YFP mice were killed with $\mathrm{CO}_{2}$, and subject to cardiac perfusion with $7 \mathrm{ml} \mathrm{PBS}$ with heparin, and then with $35 \mathrm{ml}$ 4\% PFA in PBS. The mouse brain was removed, postfixed in $4 \% \mathrm{PFA}$ in $\mathrm{PBS}$ at $4^{\circ} \mathrm{C}$ for $2 \mathrm{~h}$, and sectioned into 40 $\mu \mathrm{m}$ slices with a Compresstome VH-200 (Precisionary). The slices were mounted onto microscope slides (Fisher Scientific), dried at room temperature, and frozen at $-20^{\circ} \mathrm{C}$. GFP antibody was used to detect the expression levels of $\alpha 4$-YFP or $\alpha 4$-GFP nAChRs, and Alexa-555conjugated streptavidin was used to visualize neurobiotin. The brain sections were thawed and washed twice (10 min each) with cold PBS $\left(4^{\circ} \mathrm{C}\right)$, permeabilized for $45 \mathrm{~min}$ in $\mathrm{PBS} / 0.5 \%$ saponin, blocked for 45 $\mathrm{min}$ in PBS $/ 10 \%$ donkey serum, incubated in primary antibodies $(1: 500$, rabbit anti-GFP IgG, Invitrogen) or streptavidin (1:500) in PBS $/ 4 \%$ donkey serum at $4^{\circ} \mathrm{C}$ for $18 \mathrm{~h}$, washed 3 times (15 min each) in PBS, incubated in secondary antibody (1:500, Alexa-488-conjugated donkey anti-rabbit IgG, Invitrogen) in PBS/4\% donkey serum at room temperature for $1 \mathrm{~h}$. Samples were washed 3 times (10 min each) in PBS, dried at room temperature, and coverslipped with mounting medium (Vector Laboratories).

Chronic nicotine treatment. Nicotine or vehicle (saline) was administered to mice (5- to 6-week-old) by subcutaneously implanted osmotic minipumps (model 1002 or 2002, Alzet) for 7 or $14 \mathrm{~d}$ to avoid repetitive handling, which causes stress (Marks et al., 1992; Collins et al., 1994; Marks et al., 2004; Nashmi et al., 2007). On the day of minipump implantation, vehicle or (-) nicotine hydrogen tartrate was prepared 
freshly and loaded into the pump to deliver vehicle or nicotine $(2 \mathrm{mg} / \mathrm{kg} / \mathrm{h}$ at $0.5 \mu \mathrm{l} / \mathrm{h})$.

Chemicals and applications. Sigma-Aldrich furnished most of the chemicals: acetylcholine $\mathrm{Cl}(\mathrm{ACh})$; atropine sulfate; $1(\mathrm{~S}), 9(\mathrm{R})-(-)-$ bicuculline methiodide; CNQX; dihydro- $\beta$ erythroidine hydrobromide (DH $\beta \mathrm{E})$; Li DL-2-amino-5-phosphonovalerate; methyllycaconitine citrate (MLA); (-)-nicotine hydrogen tartrate (CAS 65-31-6, nicotine); RJR-2403; and SR-95531 (GABAzine). PNU282987 and tetrodotoxin were purchased from Tocris Bioscience. Stock solutions $(>1000 \times)$ were aliquoted and stored at $-20^{\circ} \mathrm{C}$. The final dilutions were freshly made before experiments and were applied by either puffing or perfusion.

Data analysis. Using Clampfit 9.2, we measured the peak amplitude of nicotinic currents, ePSCs, eIPSCs, and eEPSCs, and counted and analyzed sIPSCs and sEPSCs and firings. The decay time constants of nicotinic currents were obtained by single-exponential fitting after the signals were low-pass filtered at $1 \mathrm{kHz}$. The amplitude of eIPSCs, eEPSCs, and ePSCs was averaged from 4 to 8 traces evoked by stimuli with the same intensity. The sIPSCs, sEPSCs, and action potentials were selected by "template search," in which the template was first selected visually according to its rise and decay phase, and the criterion level was set to 4 for sIPSCs/sEPSCs, and 10 for action potentials. Nicotinic currents, sIPSCs, sEPSCs, eIPSCs, eE-

PSCs, and firing rates between two groups of neurons were compared with unpaired $t$ test, Mann-Whitney rank test, or Kolmogorov-Smirnov (K-S) test. Two-way repeated-measures ANOVA was used to analyze the attenuation of two types of $\mathrm{I}_{\mathrm{ACh}}$ during nicotine exposure.

For analysis of drug effects, frequency of sEPSCs and firings was normalized to the baseline frequency, which was obtained during the initial control period ( $2 \mathrm{~min}$ ). The mean frequency during drug application was measured at the peak of the drug response. Drug effects were expressed as percentage changes (mean \pm SEM) from baseline. The statistical significance of drug effects was assessed by a paired two-tailed $t$ test. A twotailed Student's $t$ test was used to evaluate the statistical significance of differences in drug effects (percentage change from baseline) between different situations. The $\chi^{2}$ test was used to compare the difference in the incidence of drug responsiveness (e.g., occurrence of inward currents and increase of firing rate) between different groups of neurons.

The statistical analyses were performed with the aid of SigmaPlot 11.0 (SPSS) and OpenEpi Version 2.3.1 (Dean et al., 2010). Values of $p<0.05$ were considered significant.

\section{Results}

$\alpha 4 \beta 2^{\star}$ and $\alpha 7$ nAChRs mediate distinct nicotinic responses in STN neurons

To investigate the heterogeneity of STN neurons, we examined ACh responses by directly applying ACh onto STN neurons in parasagittal mouse brain slices (Fig. 1). We added $0.5 \mu \mathrm{M}$ atropine in both the puffing solution and the perfusate to block muscarinic ACh receptor activation. We detected two types of inward currents with nonoverlapping ranges of decay time constants: $347 \pm 29 \mathrm{~ms}(n=30)$ (Fig. $\left.1 A_{1}\right)$ and $64 \pm 5 \mathrm{~ms}(n=67)$ (Fig. $\left.1 B_{1}\right)$, in $21 \%$ and $40 \%$ of neurons, respectively. The large majority of STN neurons showed spontaneous firing, and ACh application transiently increased firing rates (Fig. $1 A_{2}, B_{2}$ ). The kinetics of the firing rate responses resembled those of the two classes of ACh-evoked currents $\left(\mathrm{I}_{\mathrm{ACh}}\right)$ (Fig. $\left.1 A_{1}, A_{2}, B_{1}, B_{2}\right)$. These data indi- cate that in the STN there are at least two subtypes of nAChRs with dramatically different kinetics. Moreover, the activation of these receptors can modulate STN neurons on either the subsecond or second time scales. Additionally, we observed that $0.5 \mu \mathrm{M}$ TTX and $20 \mu \mathrm{M}$ CNQX did not change the amplitude of $\mathrm{I}_{\mathrm{ACh}}$ (faster component: $99 \pm 4 \%$ of control, $n=5, p=0.83$; slower component: $102 \pm 5 \%$ of control, $n=7, p=0.51$ ). This indicates that these currents are mainly mediated by somatodendritic nAChRs, but not by presynaptic nAChRs in axonal terminals, which often facilitate neurotransmitter release (Dani and Bertrand, 2007; Exley and Cragg, 2008; Miwa et al., 2011).

A current decay that begins during the agonist application, then, outlasts the application, may occur by three mechanisms: receptor desensitization, deactivation of receptors due to agonist dissociation, agonist diffusion, or by a combination of these factors. Therefore, we sought to exclude the contribution of agonist dissociation or diffusion in the acute ACh experiments, by applying ACh for $3 \mathrm{~s}$ (Fig. 1C,D), so that the desensitization of nAChRs can be assessed in the sustained presence of ACh. Extending ACh application from 0.1 to $3 \mathrm{~s}$ prolonged the current decay by twofold to threefold, and also magnified the contrast between decay times of the two distinct neuronal populations that exhibit the faster and slower ACh currents. With prolonged agonist application, the two average time constants differed by $\sim 9$-fold (Fig. 1E).

nAChRs are pentameric ligand-gated ion channels and are composed of various combinations of subunits (Wooltorton et al., 2003; Xiao et al., 2009a; Changeux, 2010). The nAChRs containing $\alpha 4 \beta 2$ or $\alpha 7$ subunits are widely expressed in the CNS. They have different decay times, sensitivities to nicotine, and desensitization properties. To determine whether $\alpha 4 \beta 2$ or $\alpha 7$ containing $\mathrm{nAChRs}$ mediate the slower or faster-decaying $\mathrm{I}_{\mathrm{ACh}}$ 

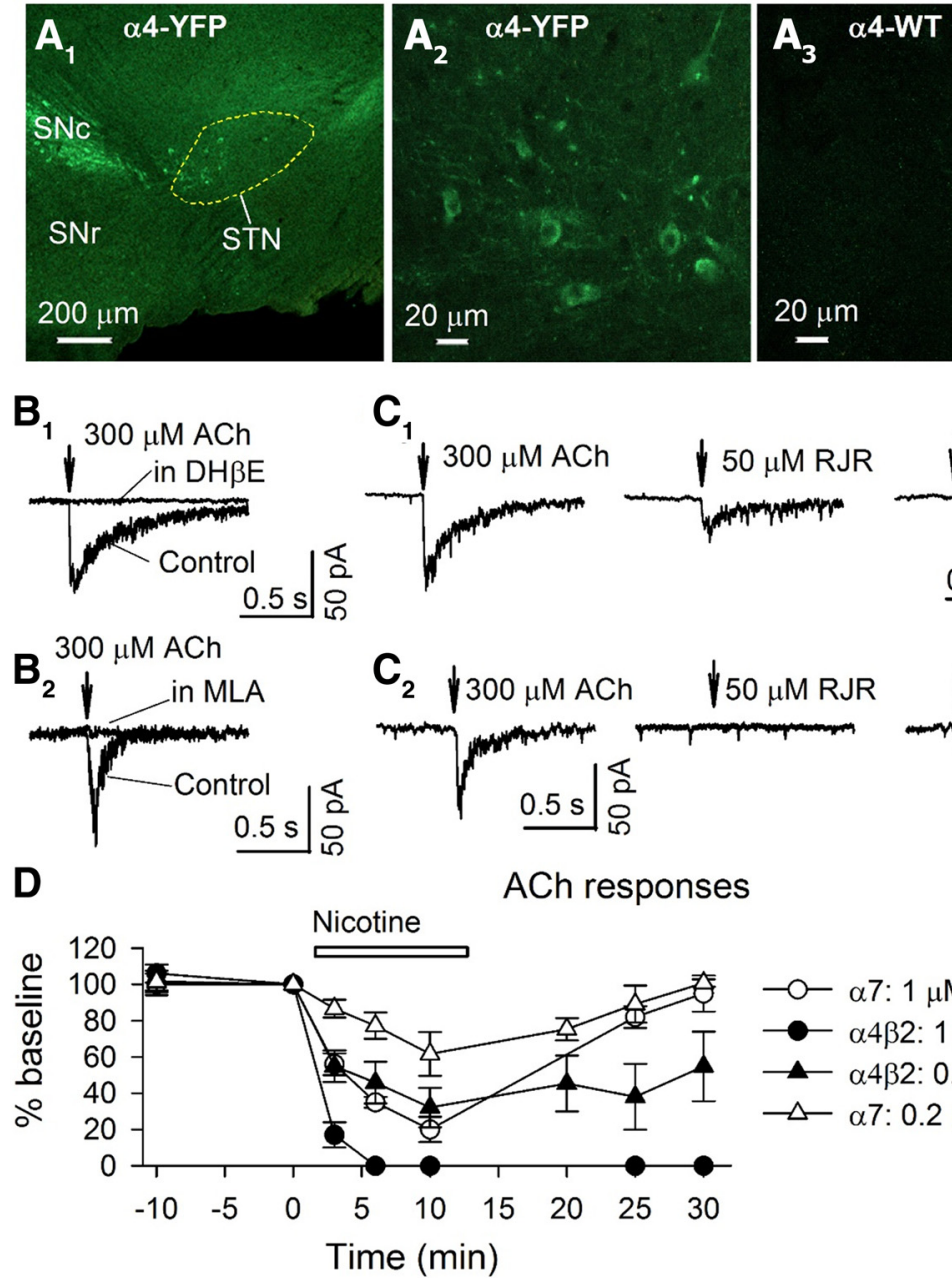

ACh responses

Figure 2. Genetically assisted pharmacological characterization of nAChR subtypes in STN neurons. $A_{1}-A_{3}$, GFP antibody staining in a PFA-fixed parasagittal brain section from either an $\alpha 4-\operatorname{YFP}\left(A_{1}, 10 \times ; A_{2}, 60 \times\right)$ or a wild-type mouse $\left(A_{3}, 60 \times\right)$. $B_{1}$ $\boldsymbol{B}_{2}$, A slower I $_{\text {ACh }}$ was abolished by $300 \mathrm{~nm} \mathrm{DH} \beta E\left(\boldsymbol{B}_{1}\right)$, whereas a faster $\mathrm{I}_{\mathrm{ACh}}$ was eliminated by $10 \mathrm{~nm} \mathrm{MLA}\left(\boldsymbol{B}_{2}\right) . \boldsymbol{C}_{1}, \mathrm{RJR}-2403$ (RJR), but not PNU-282987 (PNU), evoked an inward current in an STN neuron showing a slower $\mathrm{I}_{\mathrm{ACh}} \cdot \boldsymbol{C}_{2}, \mathrm{PNU}$-282987, but not RJR-2403, evoked an inward current in an STN neuron showing a faster $\mathrm{I}_{\mathrm{ACh}}$. Arrows indicate agonist applications $(0.1 \mathrm{~s}, 20 \mathrm{psi})$. D, Both $\alpha 4 \beta 2$ and $\alpha 7 \mathrm{nAChR}$ currents diminished during nicotine $(0.2$ and $1 \mu \mathrm{M})$ perfusion. The $\alpha 4 \beta 2 \mathrm{nAChR}$ current amplitude sharply decreased by $68 \pm 11 \%(n=6)$ and $100 \%(n=5)$ after 10 min perfusion of 0.2 (solid triangle) and $1 \mu \mathrm{m}$ (solid circle) nicotine, respectively. $\alpha 7 \mathrm{nAChR}$ currents diminished more slowly and less completely after $10 \mathrm{~min}$ nicotine perfusion ( $0.2 \mu \mathrm{m}$ nicotine: by $38 \pm 12 \%, n=5$, open triangle; $1 \mu \mathrm{m}$ nicotine: by $80 \pm 7 \%, n=5$, open circle). Two-way repeated measurements were used to compare nicotine perfusion-induced desensitization of $\alpha 4 \beta 2$ and $\alpha 7 \mathrm{nAChRs}$. For $1 \mu \mathrm{m}$ nicotine, both nAChR subtypes (df $=$ $1, F=38.7, p=0.00023)$ and nicotine exposure time $(0,3$, and $6 \mathrm{~min})(\mathrm{df}=2, F=249.2, p<0.00001)$ significantly affected nicotine effects. For $0.2 \mu \mathrm{m}$ nicotine, both $\mathrm{nAChR}$ subtypes ( $\mathrm{df}=1, F=7.2, p=0.028)$ and nicotine exposure time $(0,3$, and 6 $\min )(\mathrm{df}=2, F=26.0, p<0.00001$ ) affected nicotine effects. However, only $\alpha 7 \mathrm{nAChR}$ currents fully recovered after $15 \mathrm{~min}$ washout ( $\alpha 7: 0.2 \mu$ m nicotine: $101 \pm 2 \%$ of control, $n=5$, open triangle; $1 \mu \mathrm{m}: 82 \pm 6 \%$ of control, $n=5$, open circle) ( $\alpha 4 \beta 2$ : $0.2 \mu \mathrm{m}$ nicotine: $55 \pm 19 \%$ of control, $n=5$, solid triangle; $1 \mu \mathrm{m}: 0 \%$ of control, $n=5$, solid circle).

in STN neurons, we tested the pharmacological properties of these currents (Fig. 2).

The slower-decaying $\mathrm{I}_{\mathrm{ACh}}$ was blocked completely by $200 \mathrm{nM}$ $\mathrm{DH} \beta \mathrm{E}$, a selective antagonist of $\beta 2$-containing nAChRs (Fig. $2 B_{1}$ ). The neurons with slower-decaying $\mathrm{I}_{\mathrm{ACh}}$ responded to RJR-2403, a somewhat selective agonist for $\alpha 4 \beta 2 \mathrm{nAChRs,} \mathrm{but} \mathrm{not} \mathrm{to} \mathrm{PNU-}$ 282987, a selective agonist for $\alpha 7 \mathrm{nAChRs}$ (Fig. $2 C_{1}$ ). In contrast, the faster-decaying $\mathrm{I}_{\mathrm{ACh}}$ was inhibited by $10 \mathrm{nM}$ MLA (Fig. $2 B_{2}$ ). These same neurons responded to PNU-282987, but not to RJR2403 (Fig. $2 C_{2}$ ). These data indicate that $\alpha 4 \beta 2 \mathrm{nAChRs} \mathrm{predom-}$ inantly mediated the slower-decaying $\mathrm{I}_{\mathrm{ACh}}$, whereas $\alpha 7 \mathrm{nAChRs}$ predominantly mediated the faster-decaying $\mathrm{I}_{\mathrm{ACh}}$.
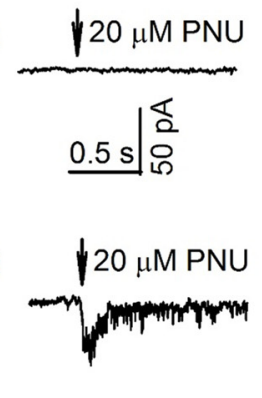

We verified the presence of $\alpha 4$ containing $\left(\alpha 4^{\star}\right)$ nAChRs in the STN by taking advantage of a knock-in mouse line in which fully functional $\alpha 4 \mathrm{nAChR}$ subunits contain yellow fluorescent protein (YFP) ( $\alpha 4$-YFP) (Nashmi et al., 2007). We conducted imaging in live brain slices from these mice and observed YFP fluorescence in $\sim 15 \%$ of STN neurons (see Fig. $5 C_{1}$ ), verifying the presence of $\alpha 4^{*}$ nAChRs in a subset of STN neurons. To further characterize $\alpha 4^{\star}$ nAChR expression, we performed immunostaining of the $\alpha 4^{*}$ nAChR protein, using the antibody to a closely related protein to YFP, GFP, in serial parasagittal sections from fixed brains of $\alpha 4$-YFP mice. Using confocal microscopy, we detected $\alpha 4^{*}$ nAChRs in some STN neurons (Fig. $\left.2 A_{1}, A_{2}\right)$, and the numbers of YFPpositive STN neurons were comparable among parasagittal sections in series from medial to lateral.

To confirm the involvement of the $\alpha 4$ subunit in nAChRs mediating the slowerdecaying $\mathrm{I}_{\mathrm{ACh}}$, we tested $\mathrm{ACh}$ responses in STN neurons of nAChR $\alpha 4$ subunit knock-out ( $\alpha 4-\mathrm{KO})$ mice. In 25 neurons from such mice, we detected only fasterdecaying $\mathrm{I}_{\mathrm{ACh}}$ but no slower-decaying current. Furthermore, the faster-decaying $\mathrm{I}_{\mathrm{ACh}}$ occurred in a proportion $(44 \%, 11$ neurons, amplitude: $138 \pm 38 \mathrm{pA} ; \tau: 54 \pm$ $10 \mathrm{~ms}$ ) of neurons in $\alpha 4-\mathrm{KO}$ mice similar to that observed in wild-type mice $(\sim 40 \%)$. These data strongly suggest that the slower-decaying $\mathrm{I}_{\mathrm{ACh}}$ in STN were predominantly mediated by $\alpha 4^{\star}$ nAChRs.

Because nicotine induces desensitization of nAChRs on various time scales, we also tested the desensitization of $\mathrm{I}_{\mathrm{ACh}}$ in the presence of 0.2 and $1 \mu \mathrm{M}$ nicotine. Repetitive ACh $(300 \mu \mathrm{M})$ applications at $>3$ min intervals evoked similar currents with $<10 \%$ variation in peak amplitude (Fig. $2 D$ ), indicating that this protocol could prevent rundown of $\mathrm{ACh}$ responses. In the presence of nicotine, $\alpha 4 \beta 2 \mathrm{nAChR}$ mediated $\mathrm{I}_{\mathrm{ACh}}$ desensitized more quickly and more completely than $\alpha 7 \mathrm{nAChR}$ mediated ones (Fig. 2D). The effects are concentrationdependent. Interestingly, after $15 \mathrm{~min}$ washout, $\alpha 7 \mathrm{nAChR}$ mediated $\mathrm{I}_{\mathrm{ACh}}$ recovered to $>82 \%$ of initial level, but $\alpha 4 \beta 2$ nAChR currents showed little or no recovery (Fig. $2 D$ ).

These data indicated that $\alpha 4 \beta 2^{*}$ and $\alpha 7$ nAChRs predominantly mediated $\mathrm{I}_{\mathrm{ACh}}$ in separate groups of STN neurons and might modulate neuronal activity in different patterns due to their deactivation and desensitization properties. These findings extend previous binding assays (Schulz et al., 1991; Pimlott et al., 2004).

We did not find significant difference in the membrane properties of STN neurons expressing $\alpha 4 \beta 2^{\star}, \alpha 7$, or no nAChRs (Table 1). In most STN neurons (no nAChRs: $73 \%, 16$ of $22 ; \alpha 7: 70 \%, 14$ of 20 ; $\alpha 4 \beta 2: 75 \%, 15$ of $\left.20, \chi^{2}=0.0003, p=0.98\right)$, injection of a negative 
Table 1. Membrane properties of STN neurons expressing different nAChRs ${ }^{a}$

\begin{tabular}{|c|c|c|c|c|c|c|c|c|}
\hline \multirow[b]{2}{*}{ Parameters } & \multicolumn{2}{|c|}{ No nAChRs } & \multicolumn{2}{|c|}{$\alpha 7$ nAChRs } & \multicolumn{3}{|c|}{$\alpha 4 \beta 2 \mathrm{nAChRs}$} & \multirow[b]{2}{*}{$p$} \\
\hline & $n$ & Value & $n$ & Value & $n$ & Value & $F_{(2)}$ & \\
\hline $\mathrm{Vm}(\mathrm{mV})$ & 22 & $-47.2 \pm 1.4$ & 20 & $-47.1 \pm 1.3$ & 21 & $-46.1 \pm 1.1$ & 0.2 & 0.83 \\
\hline $\mathrm{Rm}(\mathrm{M} \Omega)$ & 22 & $863 \pm 98$ & 20 & $793 \pm 65$ & 19 & $908 \pm 104$ & 0.4 & 0.88 \\
\hline \multicolumn{9}{|l|}{ Action potential } \\
\hline Frequency (Hz) & 18 & $4.5 \pm 0.7$ & 18 & $6.6 \pm 0.8$ & 18 & $4.3 \pm 0.7$ & 3.0 & 0.06 \\
\hline Half-width (ms) & 22 & $1.4 \pm 0.1$ & 20 & $1.1 \pm 0.1$ & 19 & $1.1 \pm 0.1$ & 1.97 & 0.14 \\
\hline Variability & 22 & $0.26 \pm 0.06$ & 20 & $0.25 \pm 0.03$ & 19 & $0.20 \pm 0.04$ & 0.45 & 0.6 \\
\hline $\mathrm{AHP}(\mathrm{mV})$ & 22 & $-14.8 \pm 0.6$ & 20 & $-17.8 \pm 1.1$ & 19 & $-17.1 \pm 0.8$ & 3.6 & 0.03 \\
\hline \multicolumn{9}{|l|}{ Hyperpolarizing response } \\
\hline Voltage sag (mV) & 16 & $10.4 \pm 1.6$ & 14 & $9.5 \pm 1.8$ & 15 & $9.5 \pm 1.2$ & 0.13 & 0.82 \\
\hline Rebound length (ms) & 19 & $447 \pm 106$ & 14 & $568 \pm 87$ & 13 & $331 \pm 105$ & 1.2 & 0.32 \\
\hline
\end{tabular}

${ }^{a}$ Values are mean \pm SE. Vm, Membrane potential; Rm, membrane resistance; AHP, afterhyperpolarization. Firing variability is the ratio of SD to average of firing rate. To measure Rm, we applied a $5 \mathrm{mV}$ hyperpolarization ( $0.5 \mathrm{~s}$ ) from a holding potential of $-50 \mathrm{mV}$, and Rm was calculated from $0 \mathrm{hm}$ 's law. Voltage sag, transient component of the hyperpolarization in response to -80 pA current injection, caused by hyperpolarization-induced inward currents $\left(I_{h}\right)$. In some neurons, a robust transient depolarization (rebound) occurred immediately after the end of the hyperpolarizing pulse. The duration of the depolarization is rebound length.

current induced a hyperpolarization with a transient component, called voltage sag, due to hyperpolarization-induced inward current $\left(I_{h}\right)$. The three types of neurons had comparable voltage sag. After the end of the hyperpolarizing pulse, we observed that the membrane potential transiently relaxed to a level more positive than the previous resting potential. This depolarization lasted a few hundred milliseconds in most STN neurons, as $\mathrm{I}_{\mathrm{h}}$ deactivated (no nAChRs: $86 \%, 19$ of 22; $\alpha 7$ : 70\%, 14 of 20; $\alpha 4 \beta 2$ : $65 \%, 13$ of $\left.20 ; \chi^{2}=3.1, p=0.08\right)$. The time course of the relaxation did not differ among the three types of neurons.

To further address the modulation of microcircuits in STN by nAChRs, we next examined GABAergic and glutamatergic synaptic inputs and synaptic targets (the $\mathrm{SN}$ ) of neurons that express either $\alpha 4 \beta 2$ or $\alpha 7 \mathrm{nAChRs}$ predominantly. To simplify the description, hereafter we refer to the two neuron types as $\alpha 4 \beta 2$ and $\alpha 7$ neurons, respectively.

\section{Synaptic inputs onto STN neurons are distinct between neuronal subtypes}

STN neurons are influenced by both glutamatergic and GABAergic inputs. To test whether these synaptic inputs onto the STN are diverse among subtypes of STN neurons, we recorded spontaneous inward and outward PSCs $\left(\mathrm{V}_{\mathrm{H}}=-50 \mathrm{mV}\right)$, which were respectively blocked by $20 \mu \mathrm{M}$ CNQX, an antagonist of non-NMDA glutamate receptors, and by GABAzine, an antagonist of $\mathrm{GABA}_{\mathrm{A}}$ receptors (Fig. $3 A$ ). At the beginning of each experiment, we applied ACh onto the recorded neuron to identify the neuron type. Interestingly, $\alpha 4 \beta 2$ neurons exhibited a twofold higher frequency of sEPSCs $\left(\mathrm{U}=62, \mathrm{n}_{1}=9, \mathrm{n}_{2}=16, p=0.006\right.$, MannWhitney Rank Sum Test), but a threefold lower frequency of sIPSCs than $\alpha 7$ neurons ( $\mathrm{U}=62, \mathrm{n}_{1}=9, \mathrm{n}_{2}=16, p<0.001$, Mann-Whitney Rank Sum Test) (Fig. 3B).

We attempted to mitigate any potential recording artifacts that could arise from our recording conditions. The Nernst potential of $\mathrm{Cl}^{-}$is $-83 \mathrm{mV}$, if we use a low $\mathrm{Cl}^{-}$( $5 \mathrm{~mm}$ ) intrapipette solution (see Materials and Methods). The electrochemical gradient, or driving force, of $\mathrm{Cl}^{-}$in this recording condition might be so small that some sIPSCs could be obscured in noise. This may result in underestimation of the sIPSC frequency. To confirm the reliability of the results, we increased the driving force for IPSCs with a higher $\mathrm{Cl}^{-}(65 \mathrm{~mm})$ intrapipette solution (see Materials and Methods). The sIPSCs were recorded from voltageclamped STN neurons $\left(\mathrm{V}_{\mathrm{H}}=-65 \mathrm{mV}\right)$ in the presence of $20 \mu \mathrm{M}$ CNQX and were blocked by $10 \mu \mathrm{M}$ bicuculline, a $\mathrm{GABA}_{\mathrm{A}}$ receptor antagonist. Under these recording conditions, we confirmed that sIPSC frequency in $\alpha 4 \beta 2$ neurons was threefold lower than that in $\alpha 7$ neurons $(\alpha 4 \beta 2: 1.3 \pm 0.4 \mathrm{~Hz}, n=7 ; \alpha 7: 5.1 \pm 1.5 \mathrm{~Hz}$, $n=20, \mathrm{U}=23, p=0.01$, Mann-Whitney Rank Sum Test). These data suggest that $\alpha 4 \beta 2$ and $\alpha 7$ neurons differ in the strength of both GABAergic and glutamatergic inputs impinging on them.

To determine whether these differences were driven by differential firing patterns in presynaptic neurons, or by differential synaptic release properties, we next examined miniature IPSCs (mIPSCs) and miniature EPSCs (mEPSCs) when neuronal firing was eliminated by $0.5 \mu \mathrm{M}$ TTX. We found that in both neuron types, mEPSCs or mIPSCs did not differ from sEPSCs or sIPSCs, respectively, in either frequency or amplitude (Fig. 3C). These data indicate that varying spike frequency in the axonal terminals did not appear to contribute to the difference in synaptic strength between $\alpha 4 \beta 2$ and $\alpha 7$ neurons.

We electrically stimulated the dorsal part of the STN and recorded EPSCs or IPSCs in STN neurons at the reversal potential of $\mathrm{Cl}^{-}(-80 \mathrm{mV})$ or of cations $(0 \mathrm{mV})$ (Fig. $\left.3 D\right)$. Using electrical stimulation giving maximal responses $(0.2 \mathrm{~ms}, 0.5 \mathrm{~mA})$, we quantified the excitatory and inhibitory inputs to the STN neurons when we clamped membrane potential at -80 and $0 \mathrm{mV}$, respectively. We observed larger evoked EPSCs but smaller evoked IPSCs in $\alpha 4 \beta 2$ neurons than in $\alpha 7$ neurons (Fig. $3 E$ ). The data suggest that $\alpha 4 \beta 2$ neurons received stronger action potential-dependent glutamatergic inputs but less GABAergic inputs than $\alpha 7$ neurons.

To address the circuit integration of glutamatergic and GABAergic inputs onto STN neuron subsets, we recorded evoked PSCs (ePSCs) at $-50 \mathrm{mV}$, which was close to the baseline membrane potentials of STN neurons. We observed PSCs that were outward in some cells (e.g., Fig. $3 F_{1}$ ) and inward in others (Fig. $3 G_{1}$ ); these were apparently compound, with two peaks (Fig. $3 F_{1}$ ) or a shoulder (Fig. $3 G_{1}$ ). For cells where electrical stimulation evoked an outward ePSC in the voltage-clamp mode, electrical stimulation delayed spontaneous spikes (lengthened interspike intervals) (Fig. $3 F_{2}$ ). Conversely, for cells where it evoked an inward ePSC in voltage-clamp mode, the electrical stimulation accelerated spontaneous spikes (shortened interspike intervals) (Fig. $3 G_{2}$ ).

The electrical stimulation-induced outward currents were rendered inward by $10 \mu \mathrm{M}$ bicuculline, and the waveform became monophasic. These remaining inward currents were blocked by $20 \mu \mathrm{M}$ CNQX (Fig. $3 F_{1}$ ). These data suggest that the outward ePSCs indicated predominance of GABAergic inputs, whereas the inward ePSCs indicated predominance of glutamatergic inputs. Indeed, the resulting compound ePSCs was significantly correlated with eEPSCs, measured at $-80 \mathrm{mV}(r=0.56, n=25$, $p=0.001$, Spearman rank order correlation), and with eIPSCs, 

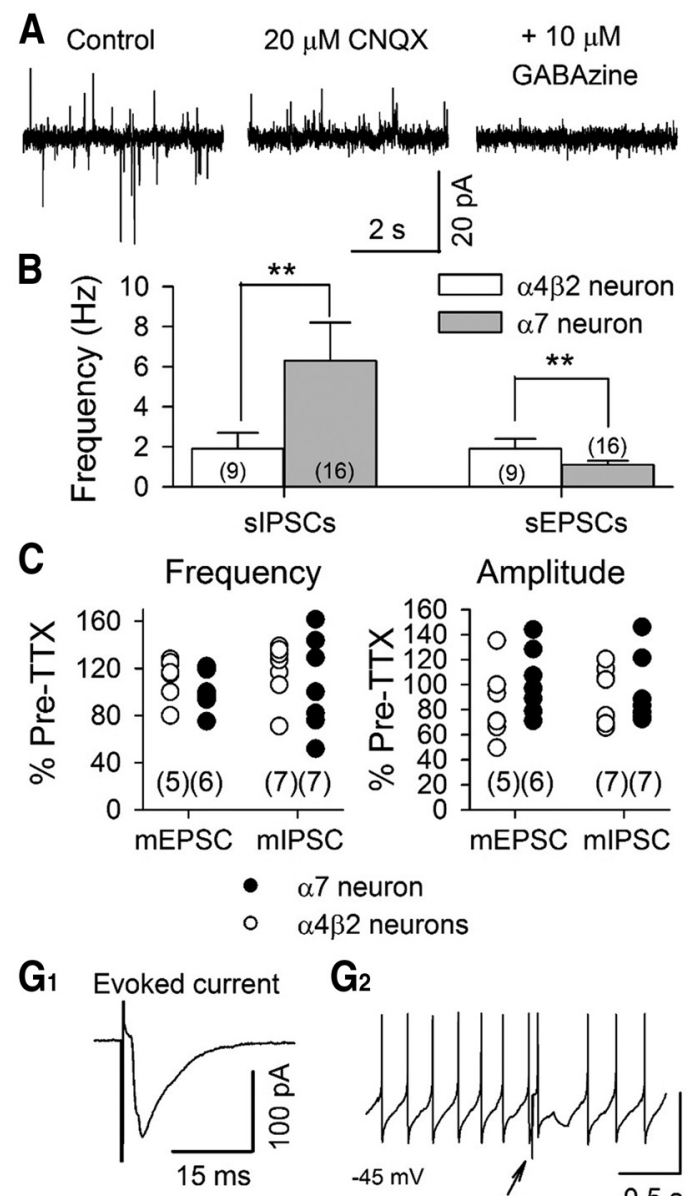

$\mathrm{G}_{2}$

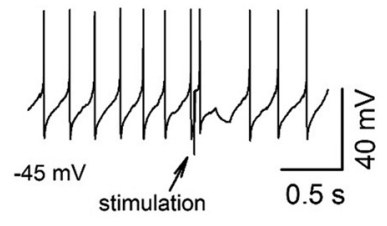

D

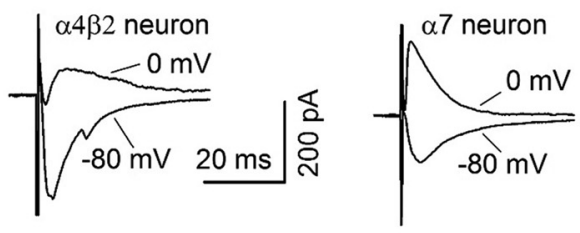

E

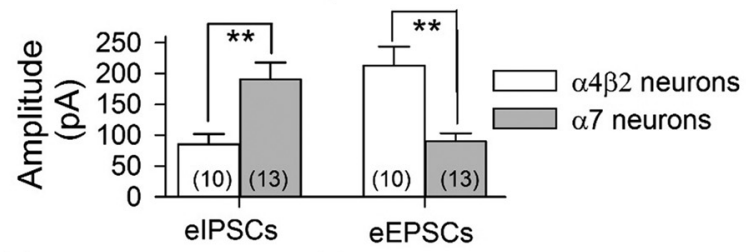

$\mathbf{F}_{1}$ $\mathbf{F}_{2}$

\section{ePSC at $-50 \mathrm{mV}$}

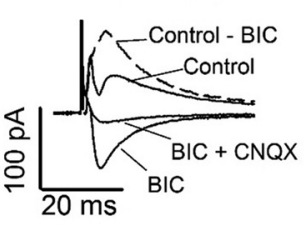

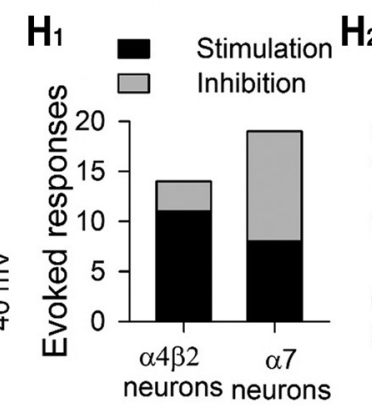

$\mathrm{H}_{2}$ Instantaneous firing rate

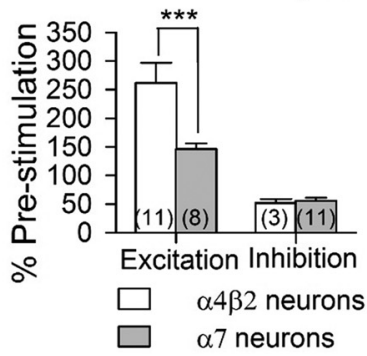

Figure 3. Glutamatergic and GABAergic synaptic inputs are diverse among STN neurons. $A$, Inward and outward spontaneous postsynaptic currents, recorded with low $\mathrm{Cl}^{-}(5 \mathrm{~mm})$ intrapipette solution (see Materials and Methods) at $V_{H}=-50 \mathrm{mV}$ (left), were blocked by $20 \mu \mathrm{M}$ CNQX (middle) and $10 \mu \mathrm{m}$ GABAzine (right), respectively. $\boldsymbol{B}$, The sIPSC and sEPSC frequency was lower (df $=$ $23, t=3.24, p<0.01$, unpaired $t$ test) and higher ( $\mathrm{df}=23, t=3.71, p<0.01$, unpaired $t$ test), respectively, in $\alpha 4 \beta 2$ neurons than in $\alpha 7$ neurons. C, TTX did not change the frequency (left) and amplitude (right) of sEPSCs and sIPSCs in $\alpha 4 \beta 2$ (blank dots) and $\alpha 7$ (dark gray dots) neurons (sEPSC frequency: $\alpha 4 \beta 2$ vs $\alpha 7, \mathrm{df}=9, t=1.41, p>0.05$; sIPSC frequency: $\alpha 4 \beta 2$ vs $\alpha 7$, df $=9$, $t=0.81, p>0.05$; sEPSC amplitude: $\alpha 4 \beta 2$ vs $\alpha 7, \mathrm{df}=9, t=0.85, p>0.05$; s IPSC amplitude: $\alpha 4 \beta 2 \mathrm{vs} \alpha 7$, df $=9, t=0.13, p>0.05$, unpaired $t$ test). Local electrical stimulation evoked larger EPSCs, but smaller IPSCs, in $\alpha 4 \beta 2$ neurons than in $\alpha 7$ neurons in STN. D, Typical traces; $E$, Summary of peak amplitude (eEPSCs: $\alpha 4 \beta 2$ vs $\alpha 7, \mathrm{df}=21, t=3.3, p<0.01$; elPSCs: $\alpha 4 \beta 2$ vs $\alpha 7$, df $=$ $21, t=3.7, p<0.01$, unpaired $t$ test). $\boldsymbol{F}_{1}$, Electrical stimulation evoked a double-peaked outward PSC ( $\mathrm{H}_{\mathrm{H}}=-50 \mathrm{mV}$ ) in an STN neuron. Bicuculline (BIC) converted this to a monophasic inward current, which was blocked by CNQX. $\boldsymbol{F}_{2}$, Local electrical stimulation changed interspike intervals in current-clamped neurons. $\boldsymbol{G}_{1}$, Electrical stimulation evoked an inward PSC $\left(\mathrm{V}_{H}=-50 \mathrm{mV}\right)$ and accelerated firing in an STN neuron $\left(\mathbf{G}_{\mathbf{2}}\right) \cdot \boldsymbol{H}_{1}$, Comparison of the proportions of $\alpha 4 \beta 2$ and $\alpha 7$ neurons being stimulated (black) or inhibited (gray) $\left(\chi^{2}=4.39, p=0.04\right)$. $\boldsymbol{H}_{2}$, Summary of electrical stimulation-evoked increase and decrease of instantaneous firing rates in $\alpha 4 \beta 2$ (blank bars) and $\alpha 7$ (gray bars) neurons. Number of neurons is indicated in parentheses. ${ }^{* *} p<0.01 ;{ }^{* * *} p<0.001$.

measured at $0 \mathrm{mV}(r=0.55, n=25, p=0.0008$, Spearman rank order correlation). The ePSC amplitude was significantly correlated with the alteration of interspike intervals $(r=0.74, n=$ $23, p<0.0001$, Spearman rank order correlation).

We observed that local electrical stimulation led to more frequent and stronger excitation of $\alpha 4 \beta 2$ neurons but caused more frequent inhibition of $\alpha 7$ neurons (Fig. $3 H_{1}, H_{2}$ ). Thus, local stimulation caused excitation in a higher percentage of $\alpha 4 \beta 2$ neurons (11 of $14,79 \%$ ) than of $\alpha 7$ neurons ( 8 of 19 , $42 \%)\left(\chi^{2}=4.39, p=0.04\right)$. Furthermore, instantaneous firing rates were increased to $262 \pm 35 \%$ of control in $\alpha 4 \beta 2$ neurons, and to $146 \pm 10 \%$ of control in $\alpha 7$ neurons ( $p=$ $0.001, \alpha 4 \beta 2$ vs $\alpha 7$ neurons, Mann-Whitney Rank Sum Test) (Fig. $3 \mathrm{H}_{2}$ ). In contrast, local stimulation led to inhibition in a lower percentage of $\alpha 4 \beta 2$ neurons ( 3 of 14,21\%) than of $\alpha 7$ neurons ( 11 of $19,58 \%)\left(\chi^{2}=4.39, p=0.04\right)$. The $\alpha 4 \beta 2$ and $\alpha 7$ neurons were similarly inhibited to $52 \pm 7 \%$ and $56 \pm 5 \%$ of control firing rates, respectively (not significantly different)
(Fig. $3 H_{2}$ ). These results support the notion that $\alpha 4 \beta 2$ neurons receive a greater proportionate share of excitation, and $\alpha 7$ neurons receive greater inhibition.

\section{$\alpha 4 \beta 2$ and $\alpha 7 \mathrm{nAChRs}$ in STN neurons differentially} modulate glutamate release onto $\mathrm{SN}$ neurons

We next wanted to understand whether the differences in the two STN populations had functional consequences downstream to their targets. We therefore turned our investigations to the targets of STN neurons, the SN. We stereotaxically injected $0.1 \mu \mathrm{l}$ BDA $(10,000,3 \%$ in saline), an anterograde tracer, in mouse STN. After 3 weeks recovery, we detected BDA-containing fibers in both the $\mathrm{SNr}$ and SNc (Fig. $4 A_{1}, A_{2}$ ), consistent with previous studies showing that STN neurons project to the SN.

As mentioned previously, STN neurons are mostly glutamatergic (Smith and Parent, 1988). To test whether synaptic projection of STN neurons to $\mathrm{SNc}$ and $\mathrm{SNr}$ are preserved in the slice preparation, we recorded evoked-EPSCs from either $\mathrm{SNr}$ 

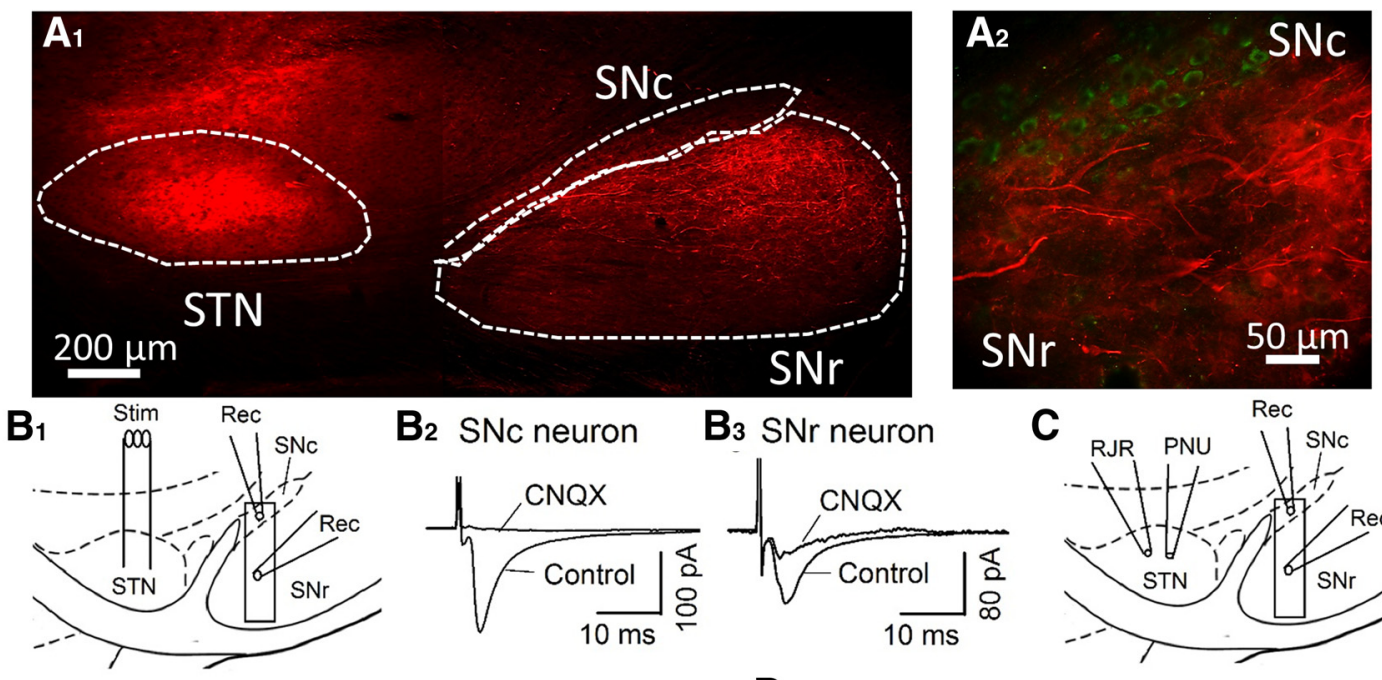

$B_{2}$ SNc neuron

$B_{3} \mathrm{SNr}$ neuron
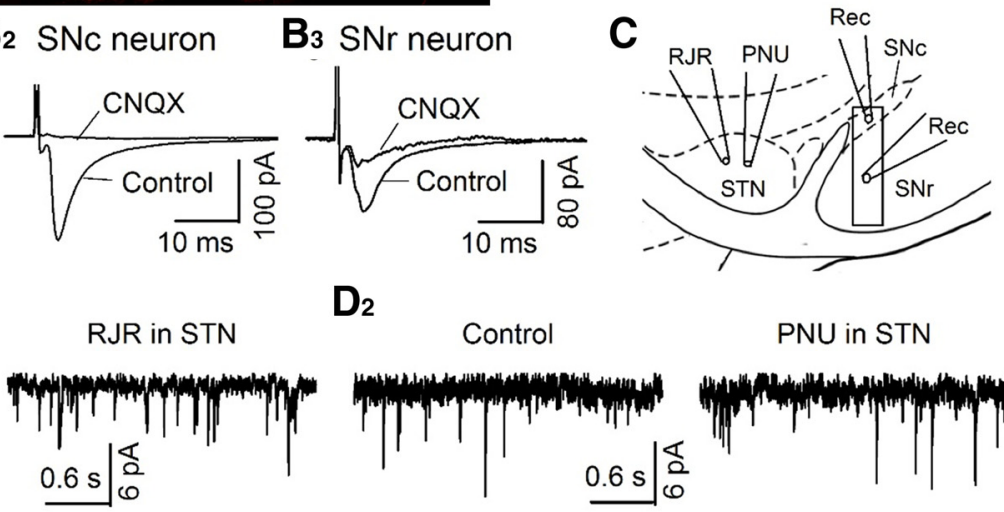

$D_{1}$ Control

RJR in STN

$\mathrm{D}_{2}$

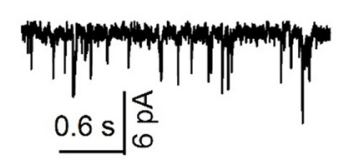

RJR in STN
Control
PNU in STN

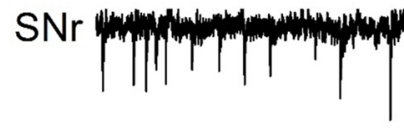

$E_{1}$ Control

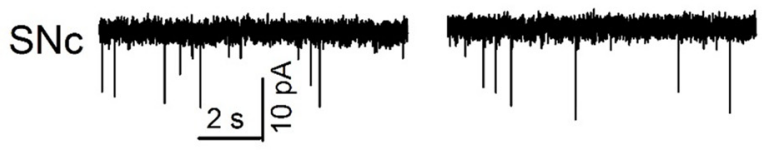

$50 \mu \mathrm{M}$ RJR in STN

$F_{1}$

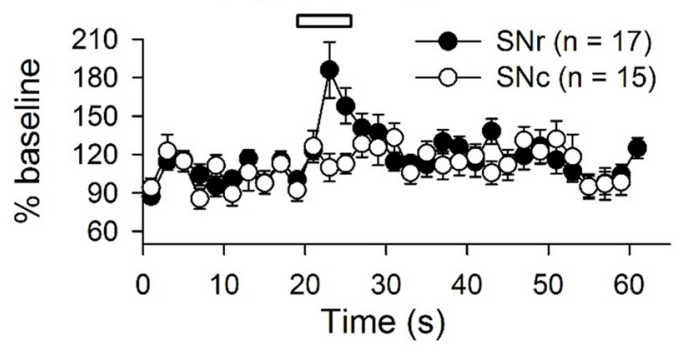

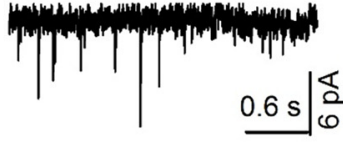

$E_{2}$

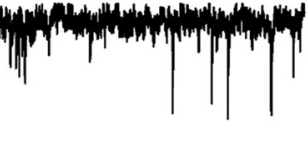

PNU in STN

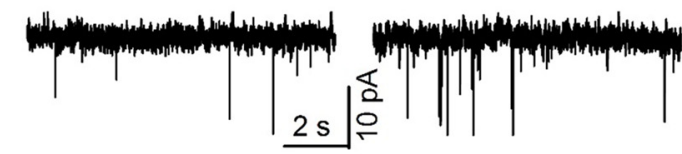

$\mathbf{F}_{\mathbf{2}}$

$20 \mu \mathrm{M}$ PNU in STN

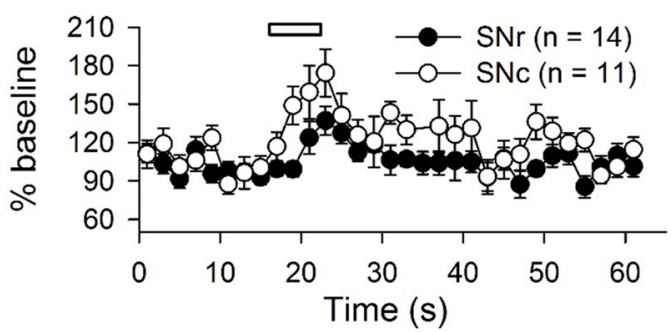

Figure 4. $\alpha 4 \beta 2$ and $\alpha 7$ neurons differentially modulate SN neurons. $\boldsymbol{A}_{1}, \boldsymbol{A}_{2}, \mathrm{BDA}\left(\right.$ red), an anterograde tracer, injected in STN, was transported to the SN. Green neurons were TH-positive $\left(\boldsymbol{A}_{2}\right)$. $\boldsymbol{B}_{1}$, A stimulating electrode (Stim) and a recording electrode (Rec) were placed in STN and SNc or SNr, respectively. $\boldsymbol{B}_{2}, \boldsymbol{B}_{3}$, In the presence of $10 \mu \mathrm{m}$ bicuculline, electrical stimulation in STN evoked CNQX- sensitive EPSCs in both SNc ( $\left.\boldsymbol{B}_{2}\right)$ and SNr neurons $\left(\boldsymbol{B}_{3}\right)$. C, Either RJR-2403 (RJR, $50 \mu \mathrm{m}$ ) or PNU-282987 (PNU, $20 \mu \mathrm{M}$ ) was locally applied (5s) to alternatively activate $\alpha 4 \beta 2$ or $\alpha 7 \mathrm{nAChRs}$ in STN. Meanwhile, sEPSCs were recorded from either an SNr neuron or an SNc neuron. Either RJR-2403 $\left(\boldsymbol{D}_{1}, \boldsymbol{E}_{1}, \boldsymbol{F}_{7}\right)$ or PNU-282987 $\left(\boldsymbol{D}_{2}, \boldsymbol{E}_{2}, \boldsymbol{F}_{2}\right)$ in STN increased sEPSC frequency in SNr neurons. PNU-282987 $\left(\boldsymbol{D}_{2}, \boldsymbol{E}_{2}, \boldsymbol{F}_{2}\right)$, but not RJR-2403 $\left(\boldsymbol{D}_{1}, \boldsymbol{E}_{1}, \boldsymbol{F}_{2}\right)$ in STN, increased SEPSC frequency in SNc neurons. $\boldsymbol{B}_{\boldsymbol{1}}$, , The rectangles in SNc and SNr indicate the area containing the recorded neurons.

GABAergic or SNc DA neurons by electrically stimulating STN in the presence of $10 \mu \mathrm{M}$ bicuculline. Evoked EPSCs were detected in all tested neurons in $\mathrm{SNr}(n=4)$ and SNc $(n=3)$, and these EPSCs were blocked by adding $20 \mu \mathrm{M}$ CNQX (Fig. $4 B_{2}, B_{3}$ ). These results confirmed that STN glutamatergic projections to the $\mathrm{SN}$ were at least partially preserved in the parasagittal slices.

We activated either $\alpha 4 \beta 2$ or $\alpha 7$ neurons with specific agonists and recorded responses in the SN. We focally ejected $50 \mu \mathrm{M}$ RJR2403 in STN for $5 \mathrm{~s}$ to stimulate $\alpha 4 \beta 2$ neurons, or $20 \mu \mathrm{M}$ PNU282987 in STN for $5 \mathrm{~s}$ to stimulate $\alpha 7$ neurons. We recorded sEPSCs from voltage-clamped SNc dopaminergic neurons or $\mathrm{SNr}$ GABAergic neurons $\left(\mathrm{V}_{\mathrm{H}}=-65 \mathrm{mV}\right)$. The frequency of sEPSCs in SNr GABAergic neurons $(4.6 \pm 0.7, n=14)$ is 2.5 -fold higher than in SNc DA neurons $(1.9 \pm 0.3, n=11)(\mathrm{df}=23, t=$ 3.57, $p=0.002$, unpaired $t$ test). Local ejection of RJR-2403 in STN increased sEPSC frequency in SNr GABAergic neurons to
$157 \pm 6 \%$ of baseline $\left(n=17, p<0.0001\right.$; Fig. $\left.4 D_{1}, F_{1}\right)$, but in SNc DA neurons to only $113 \pm 7 \%$ of baseline $(n=15, p=0.6$; Fig. $\left.4 E_{1}, F_{1}\right)(\mathrm{df}=30, t=3.39, p=0.0009, \mathrm{SNc}$ vs $\mathrm{SNr}$, unpaired $t$ test). Local ejection of PNU-282987 in STN had an opposite profile, increasing sEPSC frequency in SNr GABAergic neurons to $123 \pm 7 \%$ of baseline $\left(n=14, p=0.006\right.$; Fig. $\left.4 D_{2}\right)$, but to $160 \pm$ $8 \%$ of baseline $\left(n=10, p<0.0001\right.$; Fig. $\left.4 E_{2}\right)$ in SNc DA neurons $\left(\mathrm{df}=22, t=6.1, p<0.0001\right.$, SNc vs SNr; Fig. $\left.4 F_{2}\right)$. These data suggest that $\alpha 4 \beta 2$ neurons preferentially stimulate downstream SNr GABAergic neurons, whereas $\alpha 7$ neurons preferentially stimulate SNc dopaminergic neurons.

Using the same puffing procedure, we applied a fluorescent dye, DiI, into the STN for $5 \mathrm{~s}$, and it spread spherically, to a radius of $\sim 50 \mu \mathrm{m}(\sim 1 / 10$ of STN $)$. We applied the agonists at their $\mathrm{EC}_{50}$, which may not maximally activate nAChRs. 

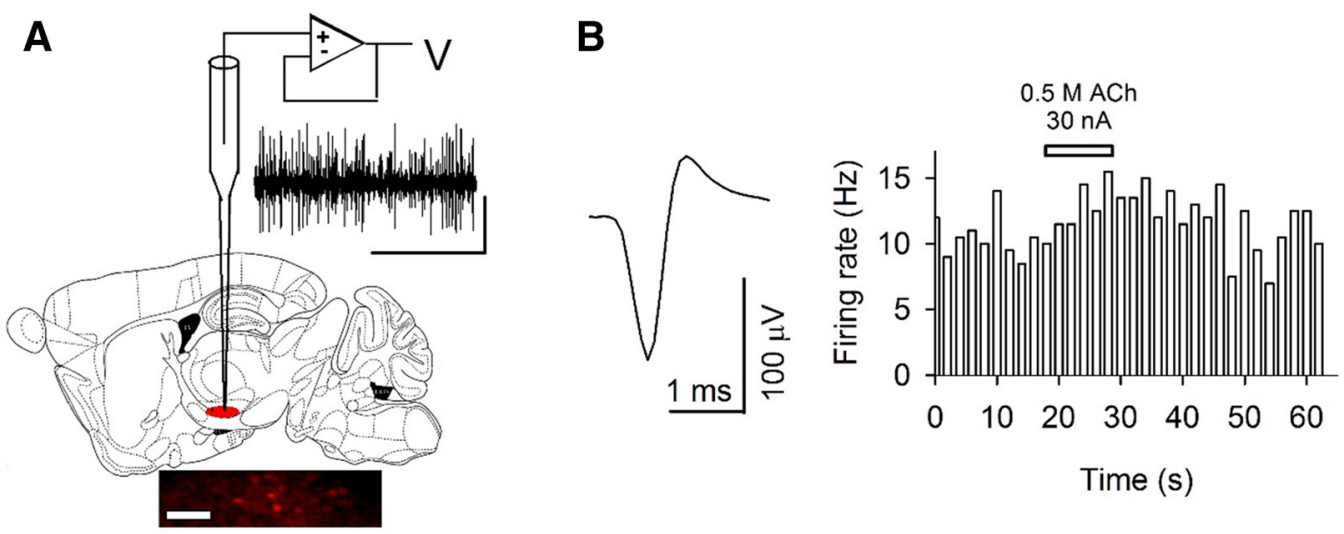

$\mathrm{C}_{1}$
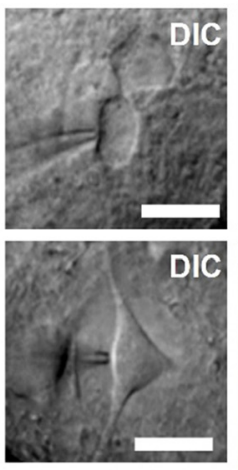

$D_{1}$

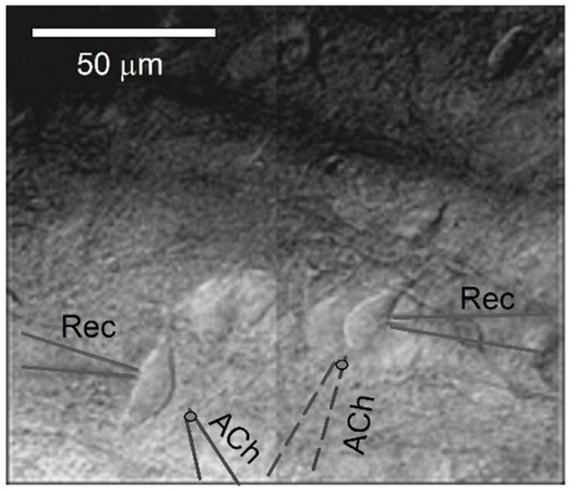

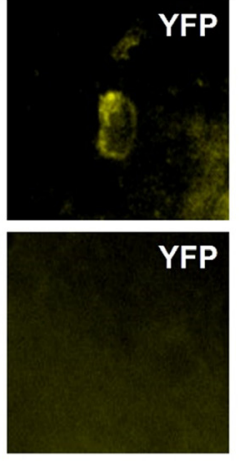

$\mathrm{C}_{2}$

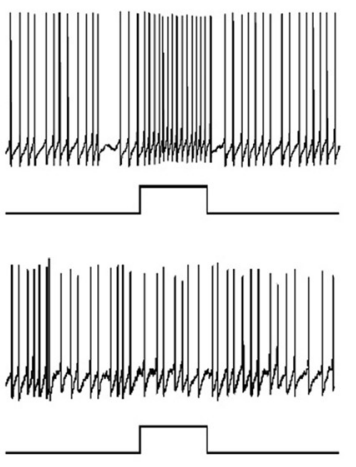

Firing rate in in vitro STN neurons

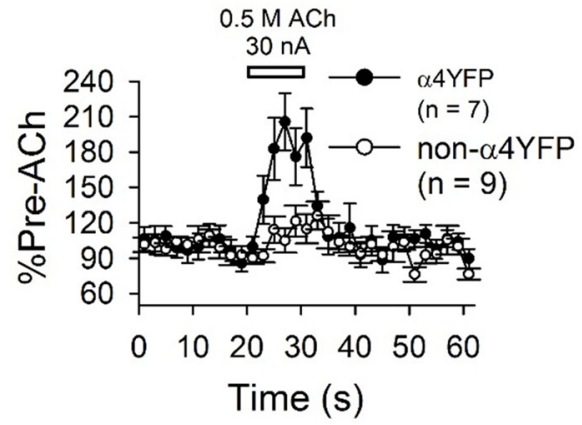

$\mathbf{D}_{2}$ Current-clamped neuron

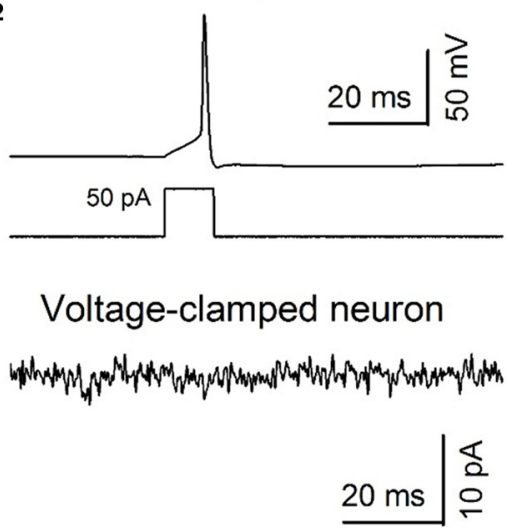

Figure 5. ACh iontophoresis directly stimulated $\alpha 4 \beta 2$ neurons in vivo and in vitro. A, Single-unit recordings were performed in STN. A typical $1 \mathrm{~s}$ trace is shown. Calibration: $0.5 \mathrm{~s}$, $150 \mu \mathrm{V}$. A representative image shows neurobiotin staining in STN. Scale bar, $100 \mu \mathrm{m} . \boldsymbol{B}, A C h(0.5 \mathrm{~m})$ was applied from the recording electrode by iontophoresis $(10 \mathrm{~s}, 30 \mathrm{nA})$, and stimulated an STN neuron (right). Left, Spike waveform. Calibration: $1 \mathrm{~ms}, 100 \mu \mathrm{V} . \boldsymbol{C}_{1}, \boldsymbol{C}_{2}$, Brain slices of $\alpha 4$-YFP mice were prepared, and whole-cell current-clamp recordings $\left(\boldsymbol{C}_{2}\right)$ were made in either $\alpha 4$-YFP-positive $\left(\boldsymbol{C}_{1}\right.$, top, $\boldsymbol{C}_{2}$, top) or $\alpha 4$-YFP-negative $\left(\boldsymbol{C}_{1}\right.$, bottom, $\boldsymbol{C}_{2}$, bottom) neurons. Scale bars: $\boldsymbol{C}_{1}, 20 \mu \mathrm{m}$. $\boldsymbol{C}_{2}$, The square waveform under firing traces shows $10 \mathrm{~s}$ ACh application by iontophoresis $(0.5 \mathrm{~m}$ ACh, 30 $\mathrm{nA}$ ). This increased firing rate in $\alpha 4$-YFP-positive neurons (top), but not in $\alpha 4$-YFP-negative neurons (bottom). $\boldsymbol{C}_{3}$, ACh increased firing rate by $71 \pm 5 \%(n=7, p=0.006)$ in $\alpha 4$-YFP-positive neurons (filled circle), but not in $\alpha 4$-YFP-negative neurons (open circle, by $8 \pm 6 \%, n=9, p=0.50$ ) ( $\alpha 4$-YFP-positive vs negative neurons, df $=14 ; t=3.9, p<0.01$, unpaired $t$ test). $D_{1}$, A pair of STN neurons were recorded. Nicotinic responses were detected by puffing ACh $(0.1 \mathrm{~s}, 300 \mu \mathrm{m}, 20 \mathrm{psi})$ onto neurons. Rec, Recording electrode; $A C h$, puffer pipette. $\boldsymbol{D}_{2}$, In a pair of neurons, a single spike was evoked in one neuron in current-clamp mode by injecting a depolarizing current $(10 \mathrm{~ms}, 50 \mathrm{pA})$, and meanwhile signals were recorded from the other neuron in voltage-clamped mode $\left(\mathrm{V}_{\mathrm{H}}=-50 \mathrm{mV}\right)$.

\section{$\alpha 4^{\star}$ nAChRs modulate firing rates of STN neuron subsets} in vivo

We performed in vivo single-unit recordings to test the expectation that STN neurons containing nAChRs would respond to local ACh application in vivo. During single-unit recordings, ACh $(0.5 \mathrm{M})$ was delivered by iontophoresis (30 nA for $10 \mathrm{~s}$ ) (Fig. $5 A, B)$. We observed that ACh stimulated $21 \%$ (17 of 81 ) of neurons (Fig. 5B).
To address receptor subtypes mediating in vivo ACh responses, we tested the effects of ACh iontophoresis on the firing rate of STN neurons in brain slices. In this set of experiments, we used $\alpha 4$-YFP mice in which $\alpha 4 \beta 2$ neurons were visibly fluorescent (Fig. $5 C_{1}$ ). We consistently observed that ACh stimulated $\alpha 4 \beta 2$ neurons (Fig. $5 C_{2}, C_{3}$, top), but not other neurons (Fig. $5 C_{2}, C_{3}$, bottom). Atropine perfusion $(0.5 \mu \mathrm{M}, 5 \mathrm{~min})$ altered $\mathrm{ACh}$ responses in neither $\alpha 4 \beta 2$ (before atropine: $186 \pm 30 \%$ of pre- 

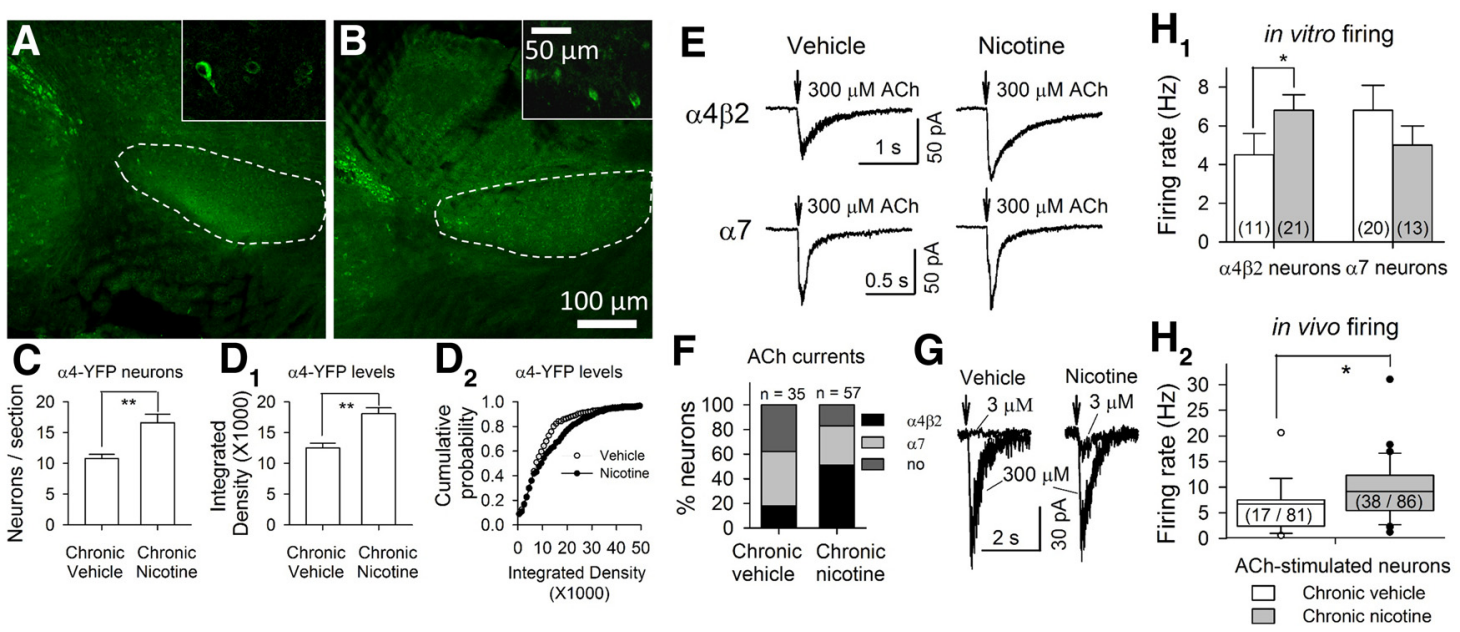

Figure 6. Chronic nicotine upregulates $\alpha 4 \beta 2$ nAChRs in STN. $\alpha 4$-YFP was visualized with GFP antibody staining $(A, B)$. More $\alpha 4$-YFP-positive neurons were found in STN of chronic nicotinetreated mice $(\boldsymbol{B})$ than chronic vehicle-treated mice $(\boldsymbol{A}) . \boldsymbol{A}, \boldsymbol{B}$, Insets, $60 \times$ images. $\boldsymbol{C}$, The number of neurons per STN section was greater in chronic nicotine-treated mice. $\boldsymbol{D}_{1}, \boldsymbol{D}_{2}$, The integrated YFP density in STN neurons was higher in chronic nicotine-treated mice. E, STN neurons in chronic nicotine-treated (14 d) mice (Nicotine) had larger $\alpha 4 \beta 2 \mathrm{nAChR}$ currents (df $=43 ; t=2.77, p=0.009$, unpaired $t$ test; $\mathrm{K}$-S statistics, $0.45, p<0.05$ ) but similar $\alpha 7 \mathrm{nAChR}$ currents, compared with those in chronic vehicle-treated mice (Vehicle). $\boldsymbol{F}$, The $14 \mathrm{~d}$ nicotine treatment increased the proportion of $\alpha 4 \beta 2$ neurons (black stack) but decreased that of neurons not responding to ACh (dark gray stack) ( $\mathrm{df}=2, \chi^{2}=10.7, p<0.01$ ). $\mathrm{G}$, The $3 \mu \mathrm{m}$ ACh induced currents in $\alpha 4 \beta 2$ neurons of $14 \mathrm{~d}$ nicotine-treated (right) mice, but not in those of $14 \mathrm{~d}$ vehicle-treated (left) mice. $\boldsymbol{H}_{1}$, The $14 \mathrm{~d}$ nicotine treatment increased spontaneous firing rate in $\alpha 4 \beta 2 \mathrm{neurons}$ ( $\mathrm{df}=29, t=3.39, p=0.02$, unpaired $t$ test), but not in $\alpha 7$ neurons ( $\mathrm{df}=31, t=1.1, p>0.05$ ). $\boldsymbol{H}_{2}$, In chronic vehicle- and nicotine-treated mice, ACh iontophoresis in vivo stimulated $21 \%$ (17 of 81 ) and $44 \%$ (38 of 86 ), respectively, of STN neurons ( $\mathrm{df}=1, \chi^{2}=10.1, p<0.01$ ). Spontaneous firing rate was higher in STN neurons stimulated by ACh iontophoresis in chronic nicotine-treated mice than those in chronic vehicle-treated mice ( $\mathrm{df}=53, \mathrm{u}=196, p<0.01$, Mann-Whitney test). Numbers of neurons are indicated in each box. ${ }^{*} p<0.05 ;{ }^{* *} p<0.01$.

ACh, $n=6$; after atropine: $238 \pm 48 \%$ of pre-ACh, $n=5 ; t=$ $1.89, p=0.12$ ) nor non- $\alpha 4 \beta 2$ (before atropine: $108 \pm 6 \%$ of pre-ACh, $n=11$; after atropine: $97 \pm 6 \%$ of pre-ACh, $n=5 ; t=$ $1.52, p=0.15)$ neurons. These data suggest that iontophoresis delivered ACh at low concentrations, which could activate $\alpha 4 \beta 2$ nAChRs, but not the less sensitive $\alpha 7$ nAChRs.

If STN neurons interact, ACh-stimulated $\alpha 4 \beta 2$ neurons, then, could excite nearby STN neurons in vivo. To test this possibility, we recorded pairs of neurons $50-100 \mu \mathrm{m}$ apart (Fig. $5 D_{1}$ ). In each neuron pair, we injected $10 \mathrm{~ms} 50-80 \mathrm{pA}$ currents to stimulate a single spike in the current-clamped neuron and recorded signals from the voltage-clamped neuron $\left(\mathrm{V}_{\mathrm{H}}=-50 \mathrm{mV}\right.$ ) (Fig. $\left.5 D_{2}\right)$. The time-locked current in the voltage-clamped neuron initiating within $0.1-0.5 \mathrm{~ms}$ after the peak of spike in the current-clamped neuron indicates monosynaptic connections (Berry and Pentreath, 1976). We ran 10 trials at $15 \mathrm{~s}$ intervals in each pair, switched recording modes in two neurons, and ran 10 trials again. In 78 pairs of STN neurons, we elicited no time-locked postsynaptic current (Fig. $5 D_{2}$ ). These data suggest that STN neurons may not form synapses with nearby neurons $(<100 \mu \mathrm{m})$.

These results indicate that we could use ACh stimulation as an approach to identify $\alpha 4 \beta 2$ neurons in STN in vivo. Indeed, our in vivo and in vitro recordings revealed a similar percentage (20\%) of $\alpha 4 \beta 2$ neurons in STN.

\section{Chronic nicotine modifies nicotinic responses in STN neurons}

Previous studies show that chronic nicotine selectively upregulates $\alpha 4 \beta 2^{*}$, but not $\alpha 7 \mathrm{nAChRs,} \mathrm{in} \mathrm{midbrain} \mathrm{GABAergic} \mathrm{neu-}$ rons (Nashmi et al., 2007; Xiao et al., 2009a). If upregulation also occurs in STN, this could enhance the activity in $\alpha 4 \beta 2$ neurons. To address this issue, we infused vehicle or nicotine into $\alpha 4$-GFP mice with osmotic minipumps for 7 or $14 \mathrm{~d}$ and counted fluorescent neurons and measured fluorescent intensity in STN. Chronic nicotine increased the number of fluorescent neurons in
Table 2. Chronic nicotine effects on ACh currents in STN neurons

\begin{tabular}{llllll}
\hline Treatment & $n$ & Vehicle & $n$ & Nicotine & $p$ \\
\hline $7 \mathrm{~d}$ & & & & & \\
$\quad \alpha 4 \beta 2$ & 13 & $49 \pm 10$ & 15 & $63 \pm 13$ & 0.38 \\
$\quad \alpha 7$ & 18 & $87 \pm 15$ & 20 & $89 \pm 22$ & 0.95 \\
$\begin{array}{l}14 \mathrm{~d} \\
\quad \alpha 4 \beta 2\end{array}$ & 22 & $46 \pm 7$ & 23 & $73 \pm 7$ & 0.009 \\
$\quad \alpha 7$ & 19 & $94 \pm 19$ & 21 & $82 \pm 15$ & 0.37 \\
$\begin{array}{l}3 \text { weeks withdrawal } \\
\quad 4 \beta 32\end{array}$ & 11 & $35 \pm 6$ & 15 & $43 \pm 11$ & 0.55 \\
$\alpha 7$ & 11 & $93 \pm 19$ & 9 & $88 \pm 22$ & 0.86 \\
\hline
\end{tabular}

STN (Fig. 6A-C) and the average fluorescent intensity of each neuron (Fig. $6 D_{1}, D_{2}$ ).

We also compared nicotinic currents in STN neurons between chronic vehicle- and nicotine-treated mice (Fig. 6E; Table 2). We detected larger $\alpha 4 \beta 2$ currents, but similar $\alpha 7$ currents, in STN neurons from $14 \mathrm{~d}$ nicotine-treated mice, than in those from $14 \mathrm{~d}$ vehicle-treated mice (Fig. 6E; Table 2). Because $300 \mu \mathrm{M} \mathrm{ACh}$ activates the majority of $\alpha 4 \beta 2 \mathrm{nAChRs}$, and $>50 \%$ of $\alpha 7$ nAChRs (Chavez-Noriega et al., 1997; Gerzanich et al., 1997), the evoked responses likely reflect the number of nAChRs.

Interestingly, both 7 and $14 \mathrm{~d}$ nicotine-treated mice had increased proportions of $\alpha 4 \beta 2$ neurons, accompanied by decreased proportion of non-nAChR neurons (Table 3; Fig. 6F). For interpretation of this phenomenon, we propose that some neurons contain $\alpha 4 \beta 2 \mathrm{nAChRs}$ that produce little or no agonist-induced current, either because they are intracellular, otherwise inactive, or simply too sparse on the membrane. Chronic nicotine increases the plasma membrane population of these receptors so that nicotinic currents can be detected electrophysiologically.

After 3 weeks withdrawal, the percentage of $\alpha 4 \beta 2$ neurons was still significantly higher in nicotine-treated mice than that in vehicle-treated mice (Table 3). However, ACh-induced current size in chronic nicotine-treated mice became the same as that in chronic vehicle-treated mice (Table 2). The recovery in current 
Table 3. Chronic nicotine effects on $n A C h R s$ in STN neurons

\begin{tabular}{lllllllll}
\hline & Treatment & & $n$ & None, $\%$ & $\alpha 4 \beta 2, \%$ & $\alpha 7, \%$ & $\chi^{2}$ & $p$ \\
\hline \multirow{2}{*}{ Wild-type } & 7d & Vehicle & 41 & 41 & 22 & 37 & 6.46 & 0.03 \\
& & Nicotine & 36 & 16 & 42 & 42 & & \\
& \multirow{2}{*}{ 14d } & Vehicle & 35 & 38 & 18 & 44 & 11.5 & 0.003 \\
& \multirow{2}{*}{ 3 weeks } & Nicotine & 57 & 17 & 51 & 32 & & \\
& withdrawal & Vehicle & 50 & 38 & 20 & 42 & 5.97 & 0.05 \\
\multirow{2}{*}{$\alpha 4$ K0 } & Naicotine & 23 & 26 & 48 & 26 & & \\
\hline
\end{tabular}

size of $\alpha 4 \beta 2 \mathrm{nAChRs}$ after nicotine withdrawal supports the notion that nicotine upregulation of nAChRs was reversible.

An extensive electrophysiological literature, mostly with nAChRs expressed in clonal cell lines, suggests that $\alpha 4 \beta 2 \mathrm{nAChRs} \mathrm{exist} \mathrm{in}$ two forms (Buisson and Bertrand, 2001; López-Hernández et al., 2004; Moroni et al., 2006; Son et al., 2009). These are termed high-sensitivity $\left(\mathrm{EC}_{50} \sim 1 \mu \mathrm{M}\right)$ and low-sensitivity $\left(\mathrm{EC}_{50} \sim 90\right.$ $\mu \mathrm{M})$ forms. The high-sensitivity form is capable of being activated by the ambient ACh and can be upregulated by chronic exposure to nicotine (Son et al., 2009; Henderson et al., 2014). Within the technical limitations of puffer application in the slice preparation, we studied this point for STN neurons. We chose to study the responses to $3 \mu \mathrm{M} \mathrm{ACh}$, which activates some highsensitivity but essentially no low-sensitivity $\alpha 4 \beta 2$ nAChRs. In such cases, an increased proportion likely reflects enhanced sensitivity (rather than simple number) of upregulated nAChRs. We applied $3 \mu \mathrm{M}$ ACh to STN neurons from both $14 \mathrm{~d}$ nicotine- and vehicle-treated mice that responded to $300 \mu \mathrm{M}$ ACh with slow currents (Fig. 6G). We detected $3 \mu \mathrm{M}$ ACh-evoked current in only 2 of 6 neurons of vehicle-treated mice $(3.7 \pm 2.5 \%$ of $300 \mu \mathrm{M}$ ACh-induced currents, $n=6$ ), but in all of 6 neurons from nicotine-treated mice ( $13.4 \pm 0.6 \%$ of $300 \mu \mathrm{M}$ ACh-induced currents, $n=6)$ ( $p=0.01$, chronic nicotine vs chronic vehicle, MannWhitney Rank Sum Test). The data are consistent with the notion that chronic nicotine upregulates high-sensitivity $\alpha 4 \beta 2$ nAChRs and can explain that spontaneous firing rate of $\alpha 4 \beta 2$ neurons was significantly higher in $14 \mathrm{~d}$ nicotine-treated mice than in $14 \mathrm{~d}$ vehicletreated mice (Fig. $6 H_{1}$ ), suggesting that $\alpha 4 \beta 2 \mathrm{nAChRs}$ on these neurons have an enhanced response to ambient ACh.

To test whether chronic nicotine upregulation of $\alpha 4 \beta 2$ nAChRs in STN neurons modifies neural circuits and neuronal activity in vivo, we conducted in vivo single-unit recordings from either chronic vehicle- or nicotine-treated mice. We observed that chronic nicotine treatment increased the proportion of neurons being stimulated by ACh iontophoresis (chronic vehicle: $21 \%, 17$ of 81 ; chronic nicotine: $44 \%, 38$ of $86 ; \chi^{2}=10.1, p=$ 0.001 ) (Fig. $6 \mathrm{H}_{2}$ ) and that spontaneous firing rates in AChstimulated neurons were higher in chronic nicotine-treated mice than in vehicle-treated mice (Fig. $6 \mathrm{H}_{2}$ ).

Synaptic inputs to STN neurons are subject to regulation by dopamine (Shen and Johnson, 2000; Heida et al., 2008; Marani et al., 2008). Chronic exposure to nicotine, by affecting dopamine levels (Rahman et al., 2004; Lester et al., 2009; Zhang et al., 2012; Koranda et al., 2014), could affect synaptic inputs to STN neurons. To test this possibility, we analyzed spontaneous postsynaptic currents in STN neurons in chronic vehicle- and nicotine-treated mice. The sIPSC and sEPSC frequency in $\alpha 4 \beta 2$ and $\alpha 7$ neurons did not significantly differ between chronic vehicle-treated mice ( $\alpha 4 \beta 2$ neurons: sIPSCs, $1.6 \pm 0.3 \mathrm{~Hz}, n=$ 19; sEPSCs, $2.8 \pm 0.5 \mathrm{~Hz}, n=19 ; \alpha 7$ neurons: sIPSCs, $8.0 \pm 2.0$ $\mathrm{Hz}, n=19$; sEPSCs, $1.6 \pm 0.2 \mathrm{~Hz}, n=19)$ and nicotine-treated mice ( $\alpha 4 \beta 2$ neurons: sIPSCs, $1.9 \pm 0.5 \mathrm{~Hz}, n=10$; sEPSCs, $3.4 \pm$

\section{Synaptic inputs and outputs of STN neurons}

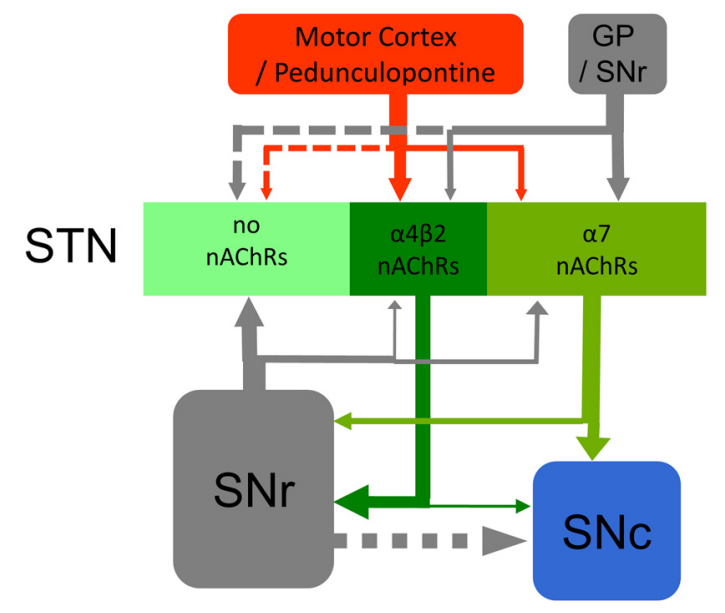

Figure 7. The diversity of synaptic inputs and outputs of STN neurons. $\alpha 4 \beta 2$ and $\alpha 7 \mathrm{nAChRs}$ are the predominant $\mathrm{nAChR}$ subtypes in $\sim 20 \%$ and $\sim 40 \%$ of STN neurons, respectively. Compared with $\alpha 7 \mathrm{nAChR}$-containing neurons, $\alpha 4 \beta 2 \mathrm{nAChR}$-containing neurons receive stronger glutamatergic inputs, primarily from the motor cortex, but less GABAergic inputs from the globus pallidus (GP). $\alpha 4 \beta 2$ and $\alpha 7 \mathrm{nAChR}$-expressing neurons preferentially control $\mathrm{SNr}$ and SNc neurons, respectively. SNr GABAergic neurons inhibit SNc neurons. Putative synaptic connections defined in other publications are indicated as dashed lines.

$0.8 \mathrm{~Hz}, n=10 ; \alpha 7$ neurons: sIPSCs, $11.2 \pm 2.8 \mathrm{~Hz}, n=15$; sEPSCs, $2.4 \pm 0.3 \mathrm{~Hz}, n=15)$. Moreover, the ratios of sIPSC frequency to sEPSC frequency in both $\alpha 4 \beta 2$ and $\alpha 7$ neurons were similar in chronic vehicle- and nicotine-treated mice ( $\alpha 4 \beta 2$ neurons, chronic vehicle: $0.71 \pm 0.11, n=19$; chronic nicotine: $0.75 \pm 0.19, n=10, p=0.84$, Mann-Whitney Rank Sum Test) ( $\alpha 7$ neurons, chronic vehicle: $8.2 \pm 3.1, n=19$; chronic nicotine: $7.6 \pm 3.1, n=15, p=0.59$, Mann-Whitney Rank Sum Test). These data suggest that chronic nicotine may not alter the excitatory and inhibitory synaptic inputs impinging on two populations of STN neurons.

\section{Discussion}

$\alpha 4 \beta 2$ and $\alpha 7 \mathrm{nAChRs}$ regulate separate microcircuits in STN We provide electrophysiological and pharmacological evidence showing two distinct microcircuits operating within the STN and diverging into $\mathrm{SNr}$ and $\mathrm{SNc}$. One, enhanced by the activation of $\alpha 7$ nAChRs, preferentially forms glutamatergic synapses onto SNc dopaminergic neurons. The other one, augmented by the activation of $\alpha 4 \beta 2 \mathrm{nAChRs,} \mathrm{preferentially} \mathrm{targets} \mathrm{SNr} \mathrm{GABAer-}$ gic inhibitory neurons. Selective stimulation of the two microcircuits may stimulate and inhibit, respectively, SNc dopaminergic neurons.

Previous studies show that a large proportion of SN neurons contain both $\alpha 4 \beta 2$ and $\alpha 7 \mathrm{nAChRs}$ (Wooltorton et al., 2003; Xiao et al., 2009a), but in the STN, $\alpha 4 \beta 2$ and $\alpha 7 \mathrm{nAChRs} \mathrm{sepa-}$ rately exist in two distinct neuron populations (Figs. 2 and 7). STN neurons containing $\alpha 4 \beta 2 \mathrm{nAChRs}$ displayed slower kinetics than STN neurons containing $\alpha 7 \mathrm{nAChRs}$ in both deactivation and desensitization (Figs. 1 and 2). Thus, the activation of $\alpha 4 \beta 2$ and $\alpha 7$ nAChRs excited STN neurons on the time scales of $>1 \mathrm{~s}$ and $<1 \mathrm{~s}$, respectively (Fig. 1). Our data also show that $\alpha 4 \beta 2 \mathrm{nAChRs}$ were only partially desensitized during agonist application at moderate concentrations (e.g., $300 \mu \mathrm{M}$ ) for several seconds (Fig. 1C), leading to maintained membrane depolarization and maintained elevation of neuronal firing rates. Given that $\alpha 4 \beta 2 \mathrm{nAChRs}$ ex- 
hibit higher sensitivity to ACh, we suggest that, in STN, $\alpha 4 \beta 2$ neurons might be among the major targets of PPTg stimulation, which boosts therapeutic effects of STN stimulation in late-phase PD (Stefani et al., 2007).

Beta oscillations, comprised of synchronized firings, occur in the STN in both PD patients and parkinsonian animals (Brown et al., 2001; Magill et al., 2004; Priori et al., 2004; Brown and Williams, 2005; Weinberger et al., 2006). High-frequency optogenetic stimulation in cortical glutamatergic inputs to STN, but not in STN neurons themselves, disrupts beta oscillations and improves motor symptoms in parkinsonian animals (Gradinaru et al., 2009). It is likely that glutamatergic inputs vary among neurons, so that stimulation of glutamatergic inputs would cause differential excitation among neurons and disrupt the oscillation. Our data showing that $\alpha 4 \beta 2$ neurons receive more glutamatergic inputs than $\alpha 7$ neurons (Fig. $3 B, D, E$ ) provide cellular and synaptic evidence for this point.

In STN neurons, we also observed $>2$-fold less GABAergic inputs in $\alpha 4 \beta 2$ than in $\alpha 7$ neurons (Fig. $3 B, D, E$ ). As GABAergic terminals synapsing onto STN neurons originate in the globus pallidus (Loucif et al., 2005; Benarroch, 2008; Marani et al., 2008), these data suggest that $\alpha 7$ neurons receive more GABAergic inputs than $\alpha 4 \beta 2$ neurons (Fig. 7).

We found that $\alpha 4 \beta 2$ neurons receive more glutamatergic inputs and less GABAergic inputs compared with $\alpha 7$ neurons (Figs. 3 and 7). Electrical stimuli in STN increased firing rate in more $\alpha 4 \beta 2$ neurons than $\alpha 7$ neurons (79\% vs $42 \%$ ) while inhibiting firing rate in more $\alpha 7$ neurons than $\alpha 4 \beta 2$ neurons (58\% vs $21 \%$ ) (Fig. $3 H_{1}$ ). This suggests that local electrical stimulation may differentially alter neuronal activity in STN.

$\alpha 4 \beta 2$ and $\alpha 7$ neurons were disparate, not only in synaptic inputs, but also in their major synaptic targets. Stimulating $\alpha 4 \beta 2$ neurons caused a greater enhancement in glutamatergic inputs to SNr GABAergic neurons, but stimulating $\alpha 7 \mathrm{nAChRs}$ caused a greater enhancement in glutamatergic input to SNc DA neurons (Fig. 4). Because SNr GABAergic neurons inhibit SNc DA neurons (Tepper et al., 1995), selectively enhancing the activity of $\alpha 4 \beta 2$ neurons in STN may indirectly inhibit SNc DA neurons. These data extended the previous finding that electrically stimulating STN neurons induces a complex postsynaptic potential waveform in SNc DA neurons, with an STN-SNc monosynaptic glutamatergic EPSP and an STN-SNr-SNc polysynaptic GABAergic IPSP (Iribe et al., 1999).

Considering our data shown in Figures 1, 2, 3, and 4 with those in Figure $5 D_{2}$ showing no synaptic interaction between STN neurons, we propose that, in the STN, there are at least two rather divergent microcircuits involving $\alpha 4 \beta 2$ or $\alpha 7$ neurons (Fig. 7). As local electrical stimulation lacks selectivity toward synaptic projections from different nuclei, further investigations are warranted to use cell typespecific manipulations to characterize the differential inputs from motor cortex/PPTg and from the globus pallidus/SNr, which is essential to fully address the circuit patterns.

Some nAChRs containing $\alpha 4$ and $\beta 2$ subunits govern voluntary movement, via activation of these nAChRs on SNc DA neurons and on DA terminals in the striatum (Labarca et al., 2001; Tapper et al., 2004; Nashmi et al., 2007; Drenan et al., 2008, 2010; Xiao et al., 2009a; Quik and Wonnacott, 2011; Drenan and Lester, 2012). Our data provide an additional pathway: a subpopulation of STN neurons can be stimulated by nicotinic agonists selective for $\alpha 4 \beta 2^{\star}$ nAChRs and may consequently excite SNr GABAergic neurons, which could increase inhibitory tone to SNc DA neurons. This pathway might be important in fine-tuning the activity of SNc DA neurons.

\section{Chronic nicotine modifies $\alpha 4 \beta 2$ nAChRs in STN neurons}

Similar to previous studies in other brain regions (Nashmi et al., 2007; Lester et al., 2009; Son et al., 2009; Xiao et al., 2009a; Srinivasan et al., 2011; Henderson et al., 2014), chronic nicotine upregulated both the number and sensitivity of $\alpha 4 \beta 2^{*} \mathrm{nAChRs}$ in STN (Fig. $6 D_{1}, D_{2}, E, G$; Table 2). Interestingly, chronic nicotine increased the percentage of $\alpha 4 \beta 2$-containing neurons; thus, there were functional $\mathrm{nAChRs}$ in neurons not previously responding to ACh (Fig. $6 \mathrm{~F}, \mathrm{H}_{2}$; Table 3). These results can be explained by previous findings show that many $\alpha 4 \beta 2 \mathrm{nAChRs}$ reside in intracellular organelles and that nicotine acts as a pharmacological chaperone to facilitate receptor assembly, so that additional receptors appear both in organelles and on the plasma membrane (Lester et al., 2009; Miwa et al., 2011; Richards et al., 2011; Srinivasan et al., 2011, 2012; Henderson et al., 2014). This upregulation may especially occur in somatodendritic regions, which give the largest signals in whole-cell recordings.

The upregulation of $\alpha 4 \beta 2^{\star}$ nAChRs by chronic nicotine enhanced responses to basal levels of $\mathrm{ACh}$ and increased firing rate in $\alpha 4 \beta 2$ neurons, but not in $\alpha 7$ neurons (Fig. $6 \mathrm{H}_{1} \mathrm{H}_{2}$ ). Because chronic nicotine changed synaptic inputs neither in $\alpha 4 \beta 2$ neurons nor in $\alpha 7$ neurons, the increased firing in $\alpha 4 \beta 2$ neurons by chronic nicotine might be primarily mediated by the upregulated $n A C h R s$ in the somata or dendrites of these neurons. According to the neural circuit diagram in Figure 7, the contrast in chronic nicotine effects on $\alpha 4 \beta 2$ and $\alpha 7$ neurons could exaggerate glutamatergic inputs to SNr GABAergic neurons over those to SNc DA neurons. The effect is demonstrated by our observation that, compared with vehicle-treated mice, chronic nicotine-treated mice had higher sEPSC frequency in SNr GABAergic neurons (vehicle: $5.0 \pm 0.6 \mathrm{~Hz}, n=18$; nicotine: $8.3 \pm 1.1 \mathrm{~Hz}, n=13, p=$ 0.006 ), but similar sEPSC frequency in SNc DA neurons (vehicle: $1.2 \pm 0.3 \mathrm{~Hz}, n=10$; nicotine: $1.5 \pm 0.4, n=8 ; p=0.24$ ). Together with the fact that chronic nicotine upregulates $\alpha 4 \beta 2^{*}$ nAChRs in SNr GABAergic neurons, but not SNc DA neurons (Nashmi et al., 2007; Xiao et al., 2009a), we propose that chronic nicotine enhances the activity of SNr GABAergic neurons through upregulating $\alpha 4 \beta 2^{\star} \mathrm{nAChRs}$ in both their somata and presynaptic STN glutamatergic neurons. This consequently could lead to a suppression and protection of SNc DA neurons (Nashmi et al., 2007; Lester et al., 2009; Xiao et al., 2009a) because GABAergic inhibition protects neurons from excitotoxicity (Luo et al., 2002).

That chronic nicotine suppresses firing in SNc DA neurons is consistent with decreased dopamine release in the striatum of chronic nicotine-treated animals, observed in previous in vivo microdialysis and in vivo cyclic voltammetry studies (Rahman et al., 2004; Zhang et al., 2012; Koranda et al., 2014). In addition, in chronic nicotine-treated animals, even when DA neuron firing frequency is directly controlled by stimulating the $\mathrm{SN}$, impulseevoked striatal dopamine release is almost as low as in $\beta 2$ knockout mice (Koranda et al., 2014). It was suggested that unknown adaptive mechanisms associated with chronically desensitized nAChRs, or with these low striatal DA levels, participate in the apparent neuroprotective effects of chronic exposure to tobacco products (Koranda et al., 2014).

The upregulation of $\alpha 4 \beta 2^{\star}$ nAChRs in STN leads to a selective enhancement of the activity in $\alpha 4 \beta 2$ neurons (Fig. $6 H_{1}, H_{2}$ ). This consequently could decrease the probability of synchronized firing, which is associated with increased beta oscillations in local field potentials, motor symptoms, and L-dopa-induced dyskinesia in PD (Kreiss et al., 1997; Lozano et al., 2000; Levy et al., 2001, 2002; Weinberger et al., 2006). This could be a possible circuit mechanism underlying the phenomenon that chronic nicotine 
partially alleviates L-dopa-induced dyskinesia in parkinsonian animal models (Huang et al., 2011). Drugs selective for $\alpha 4 \beta 2^{*}$ nAChRs could represent better candidates than nicotine because these drugs, if chronically applied, effectively upregulate $\alpha 4 \beta 2^{*}$ nAChRs (Gopalakrishnan et al., 1997; Srinivasan et al., 2014) and avoid the disadvantages of nicotine: lack of selectivity for $\mathrm{nAChR}$ subtypes and rapid metabolism.

\section{References}

Armstrong DL, Lester HA (1979) The kinetics of tubocurarine action and restricted diffusion within the synaptic cleft. J Physiol 294:365-386. CrossRef Medline

Benabid AL, Chabardes S, Mitrofanis J, Pollak P (2009) Deep brain stimulation of the subthalamic nucleus for the treatment of Parkinson's disease. Lancet Neurol 8:67-81. CrossRef Medline

Benarroch EE (2008) Subthalamic nucleus and its connections: anatomic substrate for the network effects of deep brain stimulation. Neurology 70:1991-1995. CrossRef Medline

Bergman H, Wichmann T, Karmon B, DeLong MR (1994) The primate subthalamic nucleus: II. Neuronal activity in the MPTP model of parkinsonism. J Neurophysiol 72:507-520. Medline

Berry MS, Pentreath VW (1976) Criteria for distinguishing between monosynaptic and polysynaptic transmission. Brain Res 105:1-20. CrossRef Medline

Bordia T, Campos C, Huang L, Quik M (2008) Continuous and intermittent nicotine treatment reduces L-3,4-dihydroxyphenylalanine (L-DOPA)induced dyskinesias in a rat model of Parkinson's disease. J Pharmacol Exp Ther 327:239-247. CrossRef Medline

Breit S, Schulz JB, Benabid AL (2004) Deep brain stimulation. Cell Tissue Res 318:275-288. CrossRef Medline

Brown P, Williams D (2005) Basal ganglia local field potential activity: character and functional significance in the human. Clin Neurophysiol 116: 2510-2519. CrossRef Medline

Brown P, Oliviero A, Mazzone P, Insola A, Tonali P, Di Lazzaro V (2001) Dopamine dependency of oscillations between subthalamic nucleus and pallidum in Parkinson's disease. J Neurosci 21:1033-1038. Medline

Buisson B, Bertrand D (2001) Chronic exposure to nicotine upregulates the human $\alpha 4 \beta 2$ nicotinic acetylcholine receptor function. J Neurosci 21: 1819-1829. Medline

Cenci MA (2007) Dopamine dysregulation of movement control in L-DOPAinduced dyskinesia. Trends Neurosci 30:236-243. CrossRef Medline

Champtiaux N, Changeux JP (2002) Knock-out and knock-in mice to investigate the role of nicotinic receptors in the central nervous system. Curr Drug Targets CNS Neurol Disord 1:319-330. CrossRef Medline

Changeux JP (2010) Nicotine addiction and nicotinic receptors: lessons from genetically modified mice. Nat Rev Neurosci 11:389-401. CrossRef Medline

Chavez-Noriega LE, Crona JH, Washburn MS, Urrutia A, Elliott KJ, Johnson EC (1997) Pharmacological characterization of recombinant human neuronal nicotinic acetylcholine receptors $\mathrm{h} \alpha 2 \beta 2, \mathrm{~h} \alpha 2 \beta 4, \mathrm{~h} \alpha 3 \beta 2$, $\mathrm{h} \alpha 3 \beta 4, \mathrm{~h} \alpha 4 \beta 2, \mathrm{~h} \alpha 4 \beta 4$ and $\mathrm{h} \alpha 7$ expressed in Xenopus oocytes. J Pharmacol Exp Ther 280:346-356. Medline

Cimino M, Marini P, Fornasari D, Cattabeni F, Clementi F (1992) Distribution of nicotinic receptors in cynomolgus monkey brain and ganglia: localization of $\alpha 3$ subunit mRNA, $\alpha$-bungarotoxin and nicotine binding sites. Neuroscience 51:77-86. CrossRef Medline

Collins AC, Luo Y, Selvaag S, Marks MJ (1994) Sensitivity to nicotine and brain nicotinic receptors are altered by chronic nicotine and mecamylamine infusion. J Pharmacol Exp Ther 271:125-133. Medline

Dani JA, Bertrand D (2007) Nicotinic acetylcholine receptors and nicotinic cholinergic mechanisms of the central nervous system. Annu Rev Pharmacol Toxicol 47:699-729. CrossRef Medline

Dean AG, Sullivan KM, Soe MM (2010) OpenEpi: open source epidemiologic statistics for public health. Available at: www.OpenEpi.com.

Domino EF, Ni L, Zhang H (1999) Nicotine alone and in combination with L-DOPA methyl ester or the D2 agonist N-0923 in MPTP-induced chronic hemiparkinsonian monkeys. Exp Neurol 158:414-421. CrossRef Medline

Drenan RM, Lester HA (2012) Insights into the neurobiology of the nicotinic cholinergic system and nicotine addiction from mice expressing nicotinic receptors harboring gain-of-function mutations. Pharmacol Rev 64:869-879. CrossRef Medline

Drenan RM, Grady SR, Whiteaker P, McClure-Begley T, McKinney S, Miwa
JM, Bupp S, Heintz N, McIntosh JM, Bencherif M, Marks MJ, Lester HA (2008) In vivo activation of midbrain dopamine neurons via sensitized, high-affinity $\alpha 6$ nicotinic acetylcholine receptors. Neuron 60:123-136. CrossRef Medline

Drenan RM, Grady SR, Steele AD, McKinney S, Patzlaff NE, McIntosh JM, Marks MJ, Miwa JM, Lester HA (2010) Cholinergic modulation of locomotion and striatal dopamine release is mediated by $\alpha 6 \alpha 4^{*}$ nicotinic acetylcholine receptors. J Neurosci 30:9877-9889. CrossRef Medline

Exley R, Cragg SJ (2008) Presynaptic nicotinic receptors: a dynamic and diverse cholinergic filter of striatal dopamine neurotransmission. Br J Pharmacol 153 [Suppl 1]:S283-S297.

Gerzanich V, Kuryatov A, Anand R, Lindstrom J (1997) “Orphan” $\alpha 6$ nicotinic AChR subunit can form a functional heteromeric acetylcholine receptor. Mol Pharmacol 51:320-327. CrossRef Medline

Gopalakrishnan M, Molinari EJ, Sullivan JP (1997) Regulation of human $\alpha 4 \beta 2$ neuronal nicotinic acetylcholine receptors by cholinergic channel ligands and second messenger pathways. Mol Pharmacol 52:524-534. CrossRef Medline

Gradinaru V, Mogri M, Thompson KR, Henderson JM, Deisseroth K (2009) Optical deconstruction of parkinsonian neural circuitry. Science 324: 354-359. CrossRef Medline

Heida T, Marani E, Usunoff KG (2008) The subthalamic nucleus: II. Modelling and simulation of activity. Adv Anat Embryol Cell Biol 199:1-85. CrossRef Medline

Henderson BJ, Srinivasan R, Nichols WA, Dilworth CN, Gutierrez DF, Mackey ED, McKinney S, Drenan RM, Richards CI, Lester HA (2014) Nicotine exploits a COPI-mediated process for chaperone-mediated upregulation of its receptors. J Gen Physiol 143:51-66. CrossRef Medline

Huang LZ, Grady SR, Quik M (2011) Nicotine reduces L-DOPA-induced dyskinesias by acting at $\beta 2^{\star}$ nicotinic receptors. J Pharmacol Exp Ther 338:932-941. CrossRef Medline

Ichinohe N, Teng B, Kitai ST (2000) Morphological study of the tegmental pedunculopontine nucleus, substantia nigra and subthalamic nucleus, and their interconnections in rat organotypic culture. Anat Embryol (Berl) 201:435-453. CrossRef Medline

Iribe Y, Moore K, Pang KC, Tepper JM (1999) Subthalamic stimulationinduced synaptic responses in substantia nigra pars compacta dopaminergic neurons in vitro. J Neurophysiol 82:925-933. Medline

Koranda JL, Cone JJ, McGehee DS, Roitman MF, Beeler JA, Zhuang X (2014) Nicotinic receptors regulate the dynamic range of dopamine release in vivo. J Neurophysiol 111:103-111. CrossRef Medline

Kreiss DS, Mastropietro CW, Rawji SS, Walters JR (1997) The response of subthalamic nucleus neurons to dopamine receptor stimulation in a rodent model of Parkinson's disease. J Neurosci 17:6807-6819. Medline

Labarca C, Schwarz J, Deshpande P, Schwarz S, Nowak MW, Fonck C, Nashmi R, Kofuji P, Dang H, Shi W, Fidan M, Khakh BS, Chen Z, Bowers BJ, Boulter J, Wehner JM, Lester HA (2001) Point mutant mice with hypersensitive $\alpha 4$ nicotinic receptors show dopaminergic deficits and increased anxiety. Proc Natl Acad Sci U S A 98:2786-2791. CrossRef Medline

Lester HA, Fonck C, Tapper AR, McKinney S, Damaj MI, Balogh S, Owens J, Wehner JM, Collins AC, Labarca C (2003) Hypersensitive knockin mouse strains identify receptors and pathways for nicotine action. Curr Opin Drug Discov Devel 6:633-639. Medline

Lester HA, Xiao C, Srinivasan R, Son CD, Miwa J, Pantoja R, Banghart MR, Dougherty DA, Goate AM, Wang JC (2009) Nicotine is a selective pharmacological chaperone of acetylcholine receptor number and stoichiometry: implications for drug discovery. AAPS J 11:167-177. CrossRef Medline

Levy R, Dostrovsky JO, Lang AE, Sime E, Hutchison WD, Lozano AM (2001) Effects of apomorphine on subthalamic nucleus and globus pallidus internus neurons in patients with Parkinson's disease. J Neurophysiol 86: 249-260. Medline

Levy R, Ashby P, Hutchison WD, Lang AE, Lozano AM, Dostrovsky JO (2002) Dependence of subthalamic nucleus oscillations on movement and dopamine in Parkinson's disease. Brain 125:1196-1209. CrossRef Medline

López-Hernández GY, Sánchez-Padilla J, Ortiz-Acevedo A, Lizardi-Ortiz J, SalasVincenty J, Rojas LV, Lasalde-Dominicci JA (2004) Nicotine-induced upregulation and desensitization of $\alpha 4 \beta 2$ neuronal nicotinic receptors depend on subunit ratio. J Biol Chem 279:38007-38015. CrossRef Medline

Loucif KC, Wilson CL, Baig R, Lacey MG, Stanford IM (2005) Functional interconnectivity between the globus pallidus and the subthalamic nucleus in the mouse brain slice. J Physiol 567:977-987. CrossRef Medline Lozano AM, Lang AE, Levy R, Hutchison W, Dostrovsky J (2000) Neuronal 
recordings in Parkinson's disease patients with dyskinesias induced by apomorphine. Ann Neurol 47 [Suppl]:S141-S146.

Luo J, Kaplitt MG, Fitzsimons HL, Zuzga DS, Liu Y, Oshinsky ML, During MJ (2002) Subthalamic GAD gene therapy in a Parkinson's disease rat model. Science 298:425-429. CrossRef Medline

Magill PJ, Sharott A, Bolam JP, Brown P (2004) Brain state-dependency of coherent oscillatory activity in the cerebral cortex and basal ganglia of the rat. J Neurophysiol 92:2122-2136. CrossRef Medline

Magnin M, Morel A, Jeanmonod D (2000) Single-unit analysis of the pallidum, thalamus and subthalamic nucleus in parkinsonian patients. Neuroscience 96:549-564. CrossRef Medline

Marani E, Heida T, Lakke EA, Usunoff KG (2008) The subthalamic nucleus: I. Development, cytology, topography and connections. Adv Anat Embryol Cell Biol 198:1-113. CrossRef Medline

Marks MJ, Pauly JR, Gross SD, Deneris ES, Hermans-Borgmeyer I, Heinemann SF, Collins AC (1992) Nicotine binding and nicotinic receptor subunit RNA after chronic nicotine treatment. J Neurosci 12:2765-2784. Medline

Marks MJ, Rowell PP, Cao JZ, Grady SR, McCallum SE, Collins AC (2004) Subsets of acetylcholine-stimulated ${ }^{86} \mathrm{Rb}^{+}$efflux and $\left[{ }^{125} \mathrm{I}\right]$-epibatidine binding sites in C57BL/6 mouse brain are differentially affected by chronic nicotine treatment. Neuropharmacology 46:1141-1157. CrossRef Medline

Miwa JM, Freedman R, Lester HA (2011) Neural systems governed by nicotinic acetylcholine receptors: emerging hypotheses. Neuron 70:20-33. CrossRef Medline

Moroni M, Zwart R, Sher E, Cassels BK, Bermudez I (2006) $\alpha 4 \beta 2$ nicotinic receptors with high and low acetylcholine sensitivity: pharmacology, stoichiometry, and sensitivity to long-term exposure to nicotine. Mol Pharmacol 70:755-768. CrossRef Medline

Nashmi R, Xiao C, Deshpande P, McKinney S, Grady SR, Whiteaker P, Huang Q, McClure-Begley T, Lindstrom JM, Labarca C, Collins AC, Marks MJ, Lester HA (2007) Chronic nicotine cell specifically upregulates functional $\alpha 4^{\star}$ nicotinic receptors: basis for both tolerance in midbrain and enhanced long-term potentiation in perforant path. J Neurosci 27:82028218. CrossRef Medline

Nutt JG, Rufener SL, Carter JH, Anderson VC, Pahwa R, Hammerstad JP, Burchiel KJ (2001) Interactions between deep brain stimulation and levodopa in Parkinson's disease. Neurology 57:1835-1842. CrossRef Medline

Paxinos G, Franklin KBJ (2001) The mouse brain in stereotaxic coordinates, Ed 2. San Diego: Academic.

Perlmutter JS, Mink JW (2006) Deep brain stimulation. Annu Rev Neurosci 29:229-257. CrossRef Medline

Pimlott SL, Piggott M, Owens J, Greally E, Court JA, Jaros E, Perry RH, Perry EK, Wyper D (2004) Nicotinic acetylcholine receptor distribution in Alzheimer's disease, dementia with Lewy bodies, Parkinson's disease, and vascular dementia: in vitro binding study using $5-\left[{ }^{125} \mathrm{I}\right]$-A85380 Neuropsychopharmacology 29:108-116. CrossRef

Poewe W (2009) Treatments for Parkinson disease: past achievements and current clinical needs. Neurology 72 [Suppl]:S65-S73.

Priori A, Foffani G, Pesenti A, Tamma F, Bianchi AM, Pellegrini M, Locatelli M, Moxon KA, Villani RM (2004) Rhythm-specific pharmacological modulation of subthalamic activity in Parkinson's disease. Exp Neurol 189:369-379. CrossRef Medline

Quik M, Wonnacott S (2011) $\alpha 6 \beta 2^{\star}$ and $\alpha 4 \beta 2^{\star}$ nicotinic acetylcholine receptors as drug targets for Parkinson's disease. Pharmacol Rev 63:938966. CrossRef Medline

Quik M, Polonskaya Y, Gillespie A, Jakowec M, Lloyd GK, Langston JW (2000) Localization of nicotinic receptor subunit mRNAs in monkey brain by in situ hybridization. J Comp Neurol 425:58-69. CrossRef Medline

Quik M, Cox H, Parameswaran N, O’Leary K, Langston JW, Di Monte D (2007) Nicotine reduces levodopa-induced dyskinesias in lesioned monkeys. Ann Neurol 62:588-596. CrossRef Medline

Rahman S, Zhang J, Engleman EA, Corrigall WA (2004) Neuroadaptive changes in the mesoaccumbens dopamine system after chronic nicotine self-administration: a microdialysis study. Neuroscience 129:415-424. CrossRef Medline

Richards CI, Srinivasan R, Xiao C, Mackey ED, Miwa JM, Lester HA (2011) Trafficking of $\alpha 4^{*}$ nicotinic receptors revealed by superecliptic phluorin. J Biol Chem 286:31241-31249. CrossRef Medline
Schneider JS, Pope-Coleman A, Van Velson M, Menzaghi F, Lloyd GK (1998) Effects of SIB-1508Y, a novel neuronal nicotinic acetylcholine receptor agonist, on motor behavior in parkinsonian monkeys. Mov Disord 13:637-642. CrossRef Medline

Schulz DW, Loring RH, Aizenman E, Zigmond RE (1991) Autoradiographic localization of putative nicotinic receptors in the rat brain using ${ }^{125}$ I-neuronal bungarotoxin. J Neurosci 11:287-297. Medline

Shen KZ, Johnson SW (2000) Presynaptic dopamine D2 and muscarine M3 receptors inhibit excitatory and inhibitory transmission to rat subthalamic neurones in vitro. J Physiol 525:331-341. CrossRef Medline

Smith Y, Parent A (1988) Neurons of the subthalamic nucleus in primates display glutamate but not GABA immunoreactivity. Brain Res 453:353356. CrossRef Medline

Son CD, Moss FJ, Cohen BN, Lester HA (2009) Nicotine normalizes intracellular subunit stoichiometry of nicotinic receptors carrying mutations linked to autosomal dominant nocturnal frontal lobe epilepsy. Mol Pharmacol 75:1137-1148. CrossRef Medline

Srinivasan R, Pantoja R, Moss FJ, Mackey ED, Son CD, Miwa J, Lester HA (2011) Nicotine up-regulates $\alpha 4 \beta 2$ nicotinic receptors and ER exit sites via stoichiometry-dependent chaperoning. J Gen Physiol 137:59-79. CrossRef Medline

Srinivasan R, Richards CI, Xiao C, Rhee D, Pantoja R, Dougherty DA, Miwa JM, Lester HA (2012) Pharmacological chaperoning of nicotinic acetylcholine receptors reduces the endoplasmic reticulum stress response. Mol Pharmacol 81:759-769. CrossRef Medline

Srinivasan R, Henderson BJ, Lester HA, Richards CI (2014) Pharmacological chaperoning of nAChRs: a therapeutic target for Parkinson's disease. Pharmacol Res 83C:20-29. CrossRef Medline

Stefani A, Lozano AM, Peppe A, Stanzione P, Galati S, Tropepi D, Pierantozzi M, Brusa L, Scarnati E, Mazzone P (2007) Bilateral deep brain stimulation of the pedunculopontine and subthalamic nuclei in severe Parkinson's disease. Brain 130:1596-1607. CrossRef Medline

Tapper AR, McKinney SL, Nashmi R, Schwarz J, Deshpande P, Labarca C, Whiteaker P, Marks MJ, Collins AC, Lester HA (2004) Nicotine activation of $\alpha 4^{*}$ receptors: sufficient for reward, tolerance, and sensitization. Science 306:1029-1032. CrossRef Medline

Tepper JM, Martin LP, Anderson DR (1995) GABAA receptor-mediated inhibition of rat substantia nigra dopaminergic neurons by pars reticulata projection neurons. J Neurosci 15:3092-3103. Medline

Weinberger M, Mahant N, Hutchison WD, Lozano AM, Moro E, Hodaie M, Lang AE, Dostrovsky JO (2006) Beta oscillatory activity in the subthalamic nucleus and its relation to dopaminergic response in Parkinson's disease. J Neurophysiol 96:3248-3256. CrossRef Medline

Weinberger M, Hutchison WD, Dostrovsky JO (2009) Pathological subthalamic nucleus oscillations in PD: can they be the cause of bradykinesia and akinesia? Exp Neurol 219:58-61. CrossRef Medline

Wichmann T, Bergman H, DeLong MR (1994) The primate subthalamic nucleus: III. Changes in motor behavior and neuronal activity in the internal pallidum induced by subthalamic inactivation in the MPTP model of parkinsonism. J Neurophysiol 72:521-530. Medline

Wooltorton JR, Pidoplichko VI, Broide RS, Dani JA (2003) Differential desensitization and distribution of nicotinic acetylcholine receptor subtypes in midbrain dopamine areas. J Neurosci 23:3176-3185. Medline

Xiao C, Nashmi R, McKinney S, Cai H, McIntosh JM, Lester HA (2009a) Chronic nicotine selectively enhances $\alpha 4 \beta 2^{*}$ nicotinic acetylcholine receptors in the nigrostriatal dopamine pathway. J Neurosci 29:1242812439. CrossRef Medline

Xiao C, Shao XM, Olive MF, Griffin WC 3rd, Li KY, Krnjević K, Zhou C, Ye $\mathrm{JH}$ (2009b) Ethanol facilitates glutamatergic transmission to dopamine neurons in the ventral tegmental area. Neuropsychopharmacology 34: 307-318. CrossRef Medline

Ye JH, Zhang J, Xiao C, Kong JQ (2006) Patch-clamp studies in the CNS illustrate a simple new method for obtaining viable neurons in rat brain slices: glycerol replacement of $\mathrm{NaCl}$ protects CNS neurons. J Neurosci Methods 158:251-259. CrossRef Medline

Zhang L, Dong Y, Doyon WM, Dani JA (2012) Withdrawal from chronic nicotine exposure alters dopamine signaling dynamics in the nucleus accumbens. Biol Psychiatry 71:184-191. CrossRef Medline 